University of Rhode Island

DigitalCommons@URI

Open Access Dissertations

2017

\title{
The Pre-Collegiate Pipeline to Diversify the Nursing Workforce
}

Pamela L. McCue

University of Rhode Island, pam.mccue@rinimc.org

Follow this and additional works at: https://digitalcommons.uri.edu/oa_diss

\section{Recommended Citation}

McCue, Pamela L., "The Pre-Collegiate Pipeline to Diversify the Nursing Workforce" (2017). Open Access Dissertations. Paper 575.

https://digitalcommons.uri.edu/oa_diss/575

This Dissertation is brought to you for free and open access by DigitalCommons@URI. It has been accepted for inclusion in Open Access Dissertations by an authorized administrator of DigitalCommons@URI. For more information, please contact digitalcommons-group@uri.edu. 
THE PRE-COLLEGIATE PIPELINE TO DIVERSIFY

THE NURSING WORKFORCE

BY

PAMELA L. MCCUE

A DISSERTATION SUBMITTED IN PARTIAL FULFILLMENT OF THE

REQUIREMENTS FOR THE DEGREE OF

DOCTOR OF PHILOSOPHY

IN

NURSING

UNIVERSITY OF RHODE ISLAND

2017 


\section{DOCTOR OF PHILOSOPHY DISSERTATION}

OF

PAMELA L. MCCUE

APPROVED:

Dissertation Committee:

Major Professor Mary Sullivan

Diane Martins

Minsuk Shim

Nasser H. Zawia

DEAN OF THE GRADUATE SCHOOL

\section{UNIVERSITY OF RHODE ISLAND}

2017 


\begin{abstract}
In the United States, increasing racial and ethnic diversity coupled with widening health care disparities have prompted growing concern about the lack of racial and ethnic diversity in the health professions. As the largest sector of the health care workforce who practice at all levels and settings of health care, the nursing profession has the potential to widely effect changes to reduce disparities. Yet only $19 \%$ of the registered nurse workforce reflects diversity, prompting a look at pre-collegiate pathways to a nursing career. Guided by Social Cognitive Career Theory, this study examined the pre-college factors that influenced student choice in a nursing career at three points of the pipeline, high school (HS) academic achievement, college admission with a declared health care major, and entry into the nursing/health workforce. A national representative sample of 4009 youth and parents from the Longitudinal Study of American Youth (LSAY) participated over 12 data collection waves from ages 13-37. Multiple predictors of gender, race/ethnicity, peer, parent and teacher academic and college push, student selfefficacy and college expectations contributed to HS achievement $[F(13,2096)=85.64$, $\left.p<.05, R^{2}=.35\right]$. Later in the pipeline, a healthcare college major was predicted by gender, parent science push, self-efficacy, and student expectations to attend college ( $p<$ .05 ; Nagelkerke $\mathrm{R}^{2}=.15$ ). For students who became nurses, gender, SES, and student self-efficacy beliefs were significant $\left(\mathrm{p}<.05\right.$, Nagelkerke $\left.\mathrm{R}^{2}=.15\right)$, but for healthcare providers, gender, parent math push, HS teacher college push, and self-efficacy were significant $\left(\mathrm{p}<.05\right.$, Nagelkerke $\left.\mathrm{R}^{2}=.11\right)$. Clearly, math and science teachers are needed for success in nursing/health careers along with parents and teachers, but not peers. Selfefficacy was consistently important. Implications include nursing and education policy.
\end{abstract}




\section{ACKNOWLEDGEMENTS}

I would like to acknowledge and express my sincerest appreciation to my committee members, Dr Mary Sullivan, Dr Diane Martins, Dr Minsuk Shim, Dr Lynne Dunphey, and Dr Matthew Bodah for their guidance, expertise and support during this process. I would like to especially acknowledge Dr Mary Sullivan for her mentorship, consistent encouragement, and kindness throughout this scholarly journey.

I would also like to acknowledge and thank the Robert Wood Johnson Foundation, the Rhode Island Foundation, and the University of Rhode Island, College of Nursing, for their generous support of the RWJF Future of Nursing Scholars Program. I greatly appreciate the privilege and opportunity to participate in this program which provided leadership development, access to a national network of nurse scientists and leaders, mentorship, a plethora of resources including funding of my education.

I would like to thank my mother for her unwavering confidence in my abilities

which at times, far exceeded my own. I would like to thank my sons, Michael and Kevin for their support and encouragement during this journey. Thank you, Kevin, for your assistance and patience with all my internet, processing, and printing issues. Thank you to my husband, Michael, for just, everything. 


\section{TABLE OF CONTENTS}

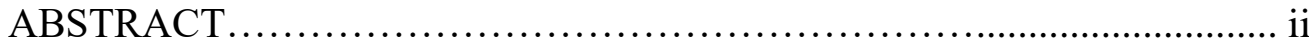

ACKNOWLEDGEMENTS...................................................................ii

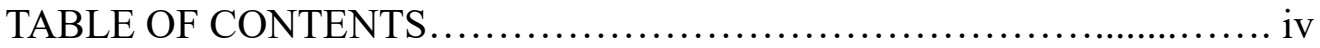

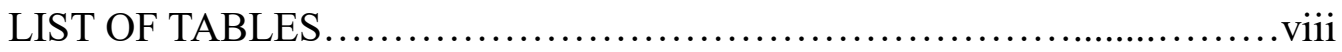

LIST OF FIGURES....................................................

CHAPTER I: INTRODUCTION .........................................

Theoretical Framework.............................................................4

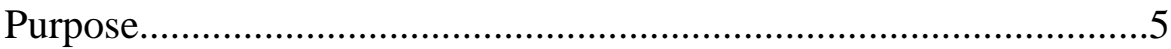

Research Questions...............................................................

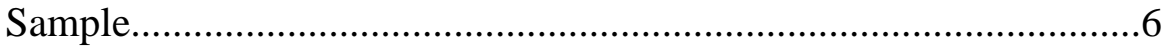

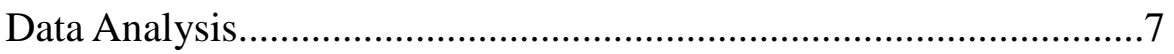

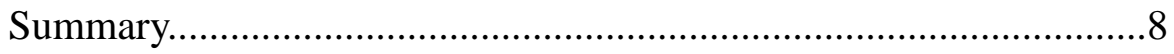

CHAPTER II: LITERATURE REVIEW ...............................10

Health Disparities..............................................10

Health Care Disparities and Equity..........................13

Current and Projected US Demographics................................14

Population Demographics.................................14

Health Professions Workforce Demographics.................15

Health Care Workforce Diversity Strategy..........................16

HRSA Diversity Conceptual Model...........................16

Nursing Workforce Diversity.............................20 
Nursing Pipeline Initiatives......................................21

Pre-Collegiate Barriers.................................................23

Pre-College Social Cognitive Factors............................................25

Theoretical Framework.........................................26

Social Learning Theory....................................................22

Self-Efficacy Theory....................................................28

Social Cognitive Theory...............................................29

Social Cognitive Career Theory Models.............................31

Model of Career Interest....................................................32

Model of Career Choice.....................................................33

Model of Career Performance..............................................34

Satisfaction and Career Self-Management Models................35

SCCT Empirical Relevance............................................36

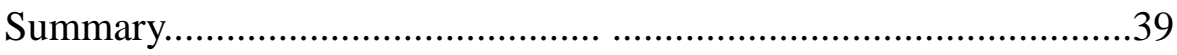

CHAPTER III: METHODOLOGY .....................................40

Longitudinal Study of American Youth...........................40

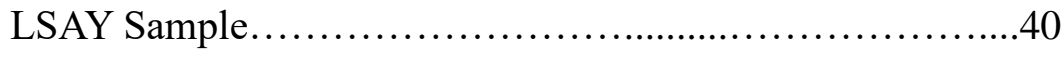

LSAY Procedures...........................................42

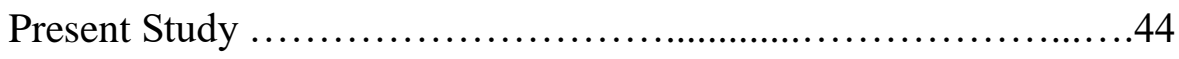

Variable Selection..............................................................45

Independent Variables..................................46

Dependent Variables......................................50

Data Analysis Plan................................................54 
Question 1 .55

Question 2 .55

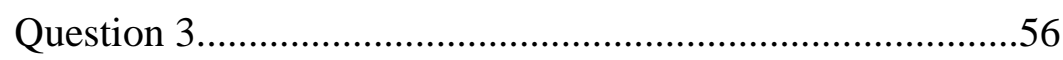

Further Analysis............................................................56

Considerations of Secondary Data Analysis............................56

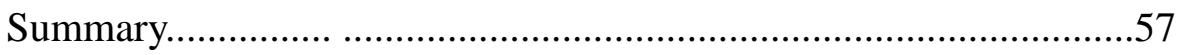

CHAPTER IV: RESULTS..............................................58

Sample........................................................58

Study Variables.............................................. 61

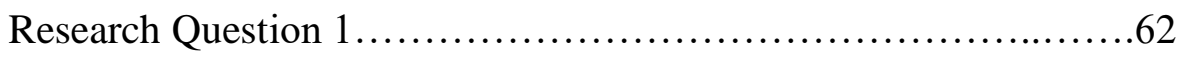

Question 1a. .......................................63

Question 1b. ........................................64

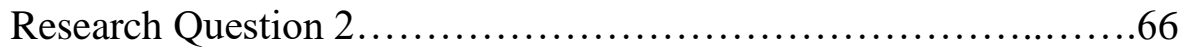

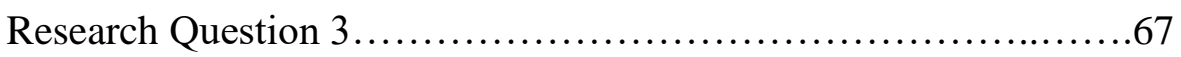

Question 3a.......................................67

Question 3b......................................69

Further Analysis....................................71

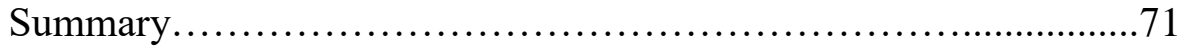

CHAPTER V: DISCUSION, CONCLUSIONS, AND IMPLICATION........73

Early Pipeline-High School........................................73

Academic Achievement....................................73

Interest in Health Care Career............................ 75

Mid-Pipeline- College .............................................. 77 
Health Care Major...........................................77

End of Pipeline-Workforce....................................78

Nursing and Health Care Workforce...................................78

Implications of Findings............................................

Implications for Theory....................................... 79

Implications for Research...................................80

Implications for Nursing Practice and Education...................81

Implications for Policy ...........................................82

Limitations of the Study..........................................83

Conclusion....................................................84

Appendix A: URI IRB Letter............................................ 85

Appendix B: SCCT Diagram of Study Variables..................................86

Appendix C: Table of Correlations .............................................. 87

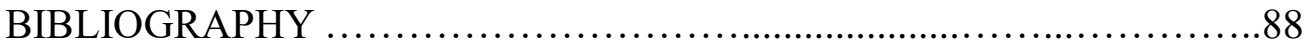




\section{LIST OF TABLES}

Table 1. Independent Variables......................................48

Table 2. Dependent Variables........................................53

Table 3. Demographic Characteristics of LSAY Sample $(N=4009) \ldots . . . . . .58$

Table 4. Demographic Characteristics of Health Care Career Interest and

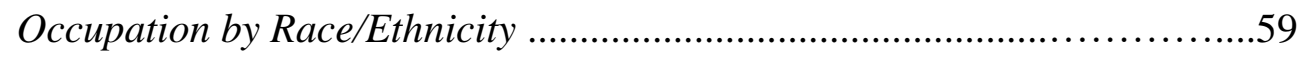

Table 5. Descriptive Statistics for the Study Variables...................... 61

Table 6. Summary Multiple Regression Analysis: Predicating Reading, Math,

Science Achievement in HS..........................................................63

Table 7. Summary Logistic Regression Analysis: Predicating Interest in

Health Care at High School Graduation.....................................................64

Table 8. Summary Logistic Regression Analysis: Predicating Interest in

Health Care at High School Graduation ...................................................66

Table 9. Summary Logistic Regression Analysis: Predicting Occupation in

Heath Care ..............................................................................68

Table 10. Summary Logistic Regression Analysis: Predicting Occupation in

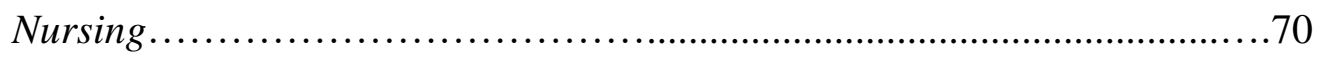

Table 11. Summary Logistic Regression Analysis: Predicting Registered Nurse

Occupation ..................................................................................... 71 


\section{LIST OF FIGURES}

Figure 1. HRSA Diversity Conceptual Model..................................17

Figure 2. Self-Efficacy Model......................................... 29

Figure 3. SCCT Career Interests Model................................... 32

Figure 4. SCCT Career Choice Model...................................... 34

Figure 5. SCCT Career Performance Model..................................35

Figure 6. Study Constructs of SCCT Career Choice Model......................46 


\section{CHAPTER I:}

\section{INTRODUCTION}

In the United States, increasing racial and ethnic diversity coupled with persistent and widening health care disparities (Institute of Medicine [IOM], 2003; Agency for Healthcare Research and Quality [AHRQ], 2016) have prompted growing concern about the lack of racial and ethnic diversity in the health professions (Beacham, Askew, \& Williams, 2009; Coffman, Rosenoff, \& Grumbach, 2001; IOM, 2004; The Sullivan Commission, 2004). When the health care workforce does not reflect the nation's shifting demographics, the risk increases for greater health disparities, reduced access to and use of health care services, gaps in cultural and linguistic competence, decreased patient satisfaction and provider choice, and diminished educational experiences for all health professions students (Carthon, Nguyen, Chittams, Park, \& Guevara, 2014; Health Resources and Services Administration, [HRSA], 2006; IOM, 2004; Saha, Taggart, Komaromy, \& Bindman, 2000). The nursing profession, by virtue of its numbers, has the potential to widely effect changes to reduce and eliminate disparities. Nurses comprise the largest sector of the healthcare workforce and they practice at all levels and across settings within health care (IOM, 2001). Yet, only $19 \%$ of the registered nurse workforce is of a race/ethnicity other than White/Caucasian, which is in sharp contrast to $37 \%$ of the United States population (National Council of State Boards of Nursing, 2013; US Census Bureau, 2012). Schools of nursing recognize the need to improve student diversity to reflect population demographics, however nurse educators have found the pool of qualified applicants dismally small (Beacham, et al., 2009). Despite decades of increased federal and philanthropic efforts to recruit and retain racially and ethnically diverse 
nursing students, progress to increase the diversity in the nursing workforce has been slow (McMenamin, 2015).

In its landmark report, Missing Persons: Minorities in the Health Professions, The Sullivan Commission (2004), identified that the lack of diversity among all health care professions was caused by inadequacies and inequities in the US public education system for students of color and low income families. On average, when compared to white students, disadvantaged students of color received a K-12 education of measurable lower quality, attended poorly funded schools, scored lower on standardized tests and had lower high school graduation rates and college attendance (The Sullivan Commission, 2004; Institute of Medicine, 2004; NCES, 2010). In high schools where half of the student enrollments were students of color, had more inexperienced teachers and more math teachers who did not have the required certifications to teach that subject compared to high schools where half the student enrollments were White (NCES, 2010). Students of color and/or low income were also more likely to receive poor high school career counseling (Manney \& Fonza-Thomason, 2010); consistent messages from high school teachers and guidance counselors that college was not a realistic option; and were disproportionality steered into lower level courses and sequences that did not meet postsecondary admission requirements (Archbald \& Farley-Ripple, 2012; Villarruel, Canales, \& Torres, 2001).

The pathway to a career in nursing begins before college. Students begin investigating career choices as early as middle school (Cohen, Palumbo, Rambur, \& Mongeon, 2004; Hoke, 2006; Knight, Abdallah, Findeisen, Devereaux-Meillo, \& Dowling, 2011), and are greatly influenced in these choices by teachers, guidance 
counselors, parents and peers (Cabrera \& La Nasa, 2000; Manney \& Fonza-Thomason, 2010; Villarruel, et al., 2001). These early influences inform decisions on selection of high school curriculum coursework, affect self-beliefs in academic achievement, which, in turn, effect eligibility for college admission (Cohen et al., 2004; Fletcher, 2012; Miller \& Kimmel, 2012; The Sullivan Commission, 2004; Villarruel et al., 2001).

Several nurse researchers, federally and philanthropically funded, have developed targeted initiatives to increase the recruitment and retention of ethnically and racially diverse students currently underrepresented in the nursing workforce. These initiatives, referred to as "nursing pipeline programs" have ranged from mere exposure to nursing as a career to programs that support student achievement at every post-secondary level (Carthon et al., 2014). Studies have reported success in recruitment strategies that included workshops and summer programs for middle and high school students, (Fleming, Berkowitz, \& Cheadle, 2005; Knight, Abdallah, Findeisen, Devereaux-Meillo, \& Dowling, 2011; Sampson 2004) and college retention strategies that included summer bridge programs, academic support, tutoring, study groups, coaching, mentoring, financial support, and social networking (Banister, Bowen-Brady, \& Winfrey, 2014; Degazon \& Mancha, 2012; Loftin, Newman, Gilden, Bond, \& Dumas, 2013; Noone, 2008). However, the lack of critical evaluations across programs using comparative outcome measures prohibits generalizing these results to inform other diversity pipeline programs and the small number of student participants in these programs have had minimal impact in increasing the overall numbers of diverse nurses in the workforce (Carthon et al., 2014).

Very little research has been conducted to understand the pre-collegiate pipeline 
and the factors that may influence students in choosing nursing as a career, nursing degree completion, and entry into the nursing workforce, specifically for minority students currently underrepresented in the nursing workforce. Nursing pipeline initiatives have focused on isolated programmatic initiatives, mostly at the postsecondary level, with little to no attention on the pre-college years, although it has been identified in the literature as a significant factor (The Sullivan Commission, 2004).

\section{Theoretical Framework}

Social Cognitive Career Theory (SCCT) is the theoretical framework used in this study. It describes the process of career development through the lifespan; at the time people form interests, make choices, achieve varying levels of success in educational and occupational pursuits, achieve work satisfaction, and navigate and adapt to situations in pursuit or within their chosen field (Lent \& Brown, 2006, 2013; Lent, Hackett, \& Brown, 1994, 2000). The SCCT framework consists of five interlocking models, however for the purpose and scope of this study, variables from the Career Choice model were used. This framework was ideal for this study because it explicitly considers gender, culture, and other aspects of human diversity within the context of career development (Lent \& Brown, 2013).

The major assumptions of SCCT are:

1. An individual's occupational or academic interests are reflective of his/her concurrent self-efficacy beliefs and outcome expectations (Lent, Brown, \& Hackett, 1994).

2. Self-efficacy beliefs and outcome expectations affect choice goals and actions both directly and indirectly (Lent et al., 1994). 
3. It is the dynamic interplay of various intrinsic and extrinsic factors mediated through a self-regulated and self-reflective process that directs behavior and career development (Lent et al., 1994).

According to SCCT, self-efficacy, or people's judgements of their capabilities to execute a certain action directly influences their outcome expectations or their anticipated benefits from this action (Bandura, 1986). Self-efficacy expectations and expected outcomes are both derived from various learning experiences that include, vicarious learning, verbal persuasion, an affective reaction (anxiety) or past performance (Bandura, 1977). Learning experiences are influenced by personal inputs and background contextual affordances or environmental factors (Lent, Brown, \& Hackett, 1994). Consequently, if one believes that he/she is capable of taking a certain action and that action will reap positive benefits, based on pervious learning experiences, then the individual will develop an interest, create goals, and direct behavior to achieve it.

\section{Purpose}

The purpose of this study was to examine the pre-collegiate nursing pipeline and to understand what early factors influenced high school students in choosing nursing as a career, directed goals for academic achievement, and college admission with a declared health/nursing major, with eventual entry into the nursing and health care provider workforce, specifically for minority students currently underrepresented in the nursing workforce.

\section{Research Questions}

1. What is the relationship of gender, race/ethnicity, socioeconomic status, verbal encouragement (push) of peers, parents and teachers, students' self-efficacy 
beliefs in math and science abilities, and students' expectations for education after high school in predicting, (a) high school achievement test scores and (b) interest in a health care career at high school graduation?

2. What is the relationship of gender, race/ethnicity, socioeconomic status, verbal encouragement (push) of peers, parents and teachers, students' self-efficacy beliefs in math and science abilities, and students' expectations for education after high school in predicting a health care major the first year of college?

3. What is the relationship of gender, race/ethnicity, socioeconomic status, verbal encouragement (push) of peers, parents and teachers, student self-efficacy beliefs in math and science abilities, and students' expectations for education after high school in predicting an (a) occupation in health care and (b) occupation as a registered nurse?

\section{Sample}

This study is a secondary data-analysis of the Longitudinal Study of American Youth (LSAY) funded by the National Science Foundation in 1985 (Miller, 1986). The LSAY was designed to examine the development of student attitudes toward achievement in science and mathematics; student interests in and plans for a career in science, mathematics, or engineering, during middle school, high school, and the first four years post-high school; and to estimate the relative influence of parents, home, teachers, school, peers, media, and selected informal learning experiences on these developmental patterns (Miller, 1986). Nursing and other health care provider careers are included in the LSAY. In 2006, additional funding was received to re-contact the original LSAY participants and data were collected on education and occupational outcomes. 
The LSAY sample for this study consisted of 4009 students from Cohort One and Cohort Two who also completed the 2007 occupational survey. The sample was a nationally representative sample of age-appropriate high school students who participated in the longitudinal LSAY study for seven consecutive years of data collection, ending 1 year (Cohort One) to 4 years (Cohort Two) after high school. Both cohorts were contacted 13 years later, when 33 to 37 years of age, to ask about their employment status and current occupation. Thus, the study sample represented the pre-collegiate pipeline through college to entry into the health professions workforce. Variables from the LSAY for this study were selected through the lens of the SCCT framework to answer the three research questions.

\section{Data Analysis}

Data analysis began with descriptive statistics to summarize the distribution, outliers, missing values, and data entry errors for each variable. Descriptive statistics examined the assumptions of normality, homoscedasticity and linearity. Correlations were examined for relationships among the variables. All the dependent variables, excluding high school achievement scores, were recoded into binary variables for a better fit to the research question being investigated. Composite variables were created for socioeconomic status and for the SCCT construct of self-efficacy. Recoding was required to measure the SCCT constructs of background contextual affordances and student selfefficacy beliefs in their math and science abilities. The three research questions were analyzed separately. Multiple regression was used to analyze the dependent variable of academic achievement (question 1a). Logistic regression was used for the dependent variables of interest in a health care career (question $1 \mathrm{~b}$ ), health care college major 
(question 2), health care occupation (question 3a) and registered nurse occupation (question 3b).

\section{Summary}

The United States is rapidly becoming a more diverse nation. Later this century, the projections are that non-white racial and ethnic groups will constitute the majority of the American population (US Census Bureau, 2012). As the nation becomes more diverse in its population, health disparities related to race and ethnicity continue to exist and in some cases, are widening (AHRQ, 2015). The representation of these groups in the nursing and health professions workforce is far below their representation in the general population (US Department of Health and Human Services [HHS], Health Resources Administration [HRSA], National Center for Health Workforce Analysis, 2015). Studies suggest that a more diverse nursing and health professions workforce would eliminate these disparities and improve patient outcomes (IOM, 2004; IOM, 2011; The Sullivan Commission, 2004). National nursing organizations including, the American Nurses Association (ANA), the American Association of Colleges of Nursing (AACN), and the Center to Champion Nursing, along with other nursing and health care organizations have made increasing the diversity of the nursing workforce a national priority. Government and philanthropic agencies such as the US Health Resources \& Services Administration (HRSA) and Robert Wood Johnson Foundation (RWJF) have directed a substantial amount of funding for programmatic initiatives and research to increase the diversity in the nursing workforce. This research study is in response to this national priority and contributes to the body of knowledge in nursing in the investigation of the early precollegiate pipeline to increase the racial and ethnic diversity of the nursing workforce 
through the lens of the social cognitive career theoretical framework. 


\section{CHAPTER II:}

\section{LITERATURE REVIEW}

Presented in this chapter is a review of the literature to establish the chain of logic connecting why an increase in the racial and ethnic diversity of the nursing workforce is one strategy to assist in the reduction and elimination of health disparities in the United States. Definitions of health disparities, health equity, and the factors that contribute to them are presented. Statistics and projections of the population demographics coupled with the makeup of the US health professions and nursing workforce are compared. A review of the recruitment and retention efforts that have been led by nursing programs to increase the number of underrepresented students is presented followed by a review of the evidence that suggests that initiatives may have greater impact if directed earlier in the educational pipeline prior to college admission. Lastly, this chapter presents an overview of the social cognitive career theory, the theoretical framework that guided this research study.

\section{Health Disparities}

The term "health disparities" has been more commonly used in the United Stated while the term "health inequities" has been used more frequently outside of this country (Carter-Pokras \& Baquet, 2002). Disparity has been defined in most dictionaries as; inequality, dissimilarity in respect of age, amount, number, or quality; a lack of similarity in a way that is not fair (Cambridge Online Dictionary, 2016; Oxford English Dictionary, 2016). Inequity is similarly defined as the fact or quality of being unfair; unfairness, partiality" something that is not fair or equal; (Cambridge Online Dictionary, 2016; Oxford English Dictionary, 2016). Consequently, the terms health disparities and health 
inequities, have been and continue to be used interchangeably in the literature (Braveman, 2006).

While the terms disparities and inequities have been accepted to have similar meaning internationally, the actual definition of "health disparities" has been inconsistent in this country (Dehlendorf, Bryant, Huddleston, Jacoby, \& Fujimoto, 2010). The National Institute of Health $(\mathrm{NIH}, 2005)$ defined health disparities as the differences in the incidence, prevalence, mortality, and burden of diseases and other adverse health conditions that exist among specific population groups in the United States. Other US government and public health agencies coined similar definitions referring to the differences among certain population groups based on race/ethnicity, disability and geographic location (HHS, 2000; CDC). However, Braveman (2006, 2011, 2014) reasoned that not all health differences were health disparities. She defined health disparities as potentially avoidable differences in health, or in health risks that policy could influence, between groups of people who were more and less advantaged socially; these differences systematically place socially disadvantaged groups at further disadvantage on health (Braveman, 2006). Braveman (2006) reasoned that the definition must capture the social justice context of "unfairness and inequitable" as the term was originally intended.

Contemporary definitions of "health disparities" have incorporated ethical and human rights principals and have focused on the subset of health differences that reflect social injustice as in the Healthy People 2020 definition. This definition states:

"A health disparity is a particular type of health difference that is closely linked with economic, social, or environmental disadvantage. Health disparities adversely affect 
groups of people who have systematically experienced greater social or economic obstacles to health based on their racial or ethnic group, religion, socioeconomic status, gender, age, or mental health; cognitive, sensory, or physical disability; sexual orientation or gender identity; geographic location; or other characteristics historically linked to discrimination or exclusion," (HHS, 2010).

In the U.S, historically underrepresented racial and ethnic groups account for a disproportionate percentage of health disparities (AHRQ, 2015; Mitchell, 2015). "People of color are more likely to be negatively affected by social determinants of health, or the daily living conditions in which people are born, live, learn, play, work, age and receive healthcare," (Mitchell, 2015, p. 67). Social determinants include socioeconomic status, adequate housing and food, quality of education, exposure to crime and violence, and access to health care services (World Health Organization [WHO], 2008). Unjust social and economic practices with a proclivity for discrimination have led to the unequal distribution of resources (education, adequate health care, political representation) leading to a complex sociopolitical environment from which many racial and ethnic health disparities have risen (Mitchell, 2015).

"People of color in the United States are more likely to experience poorer health outcomes and higher mortality rates from preventable conditions compared to their White counterparts," (Mitchell, 2015, p. 67). Substandard housing found in poor neighborhoods attribute to; higher incidences of lead poisoning in children causing low cognitive functioning and stunted growth; and exposure to pollutions and allergens that exacerbate cases of asthma (Afeiche et al., 2012; Lanphear et al., 2001; Lidsky \& Schneider, 2003). Impoverished communities often lack access to fresh produce but are dense with fast- 
food outlets contributing to poor nutrition, obesity, and the prevalence of chronic diseases associated with these factors (Woolf \& Braveman, 2012). Neighborhood socioeconomic disadvantage and high concentration of convenience stores have been linked to high tobacco use (Chuang, Cubbin, Ahn, \& Winkleby, 2005). The chronic stress of living amid multiple adverse conditions, such as unemployment, poverty, crime, and violence all negatively affect health and health outcomes (Braveman \& Gottlieb, 2014).

\section{Health Care Disparities and Equity}

"Health care disparities are one particular aspect of health disparities," (Dehlendorf et al., 2010, p. 212). Health care disparities are defined as racial and ethnic differences in the quality of healthcare that are not due to access related factors or clinical needs, preferences, and appropriateness of intervention (IOM, 2003). A large body of published research reveals that disadvantaged people of color experience a lower quality of health services, and are less likely to receive even routine medical procedures as compared to non-Hispanic White Americans even when insurance status, income, age, and severity of condition have been adjusted (Cohen, Gabriel, \& Terrel, 2002; IOM, 2002). Sources of health care disparities include stereotyping, discrimination, language barriers, and cultural unfamiliarity (IOM, 2003). "Unconscious bias may lead providers to manage disease differently in patients with different backgrounds and lead unintentionally to suboptimal health outcomes," (Moy \& Freeman, 2014, p. 3).

Health care disparities exist in diabetes management, cancer screening, smoking cessation education, and asthma management (AHRQ, 2015). African Americans, Hispanics, and poor/low income parents of children report poor communication with their health care provider as compared with non-Hispanic White and high-income families 
(AHRQ, 2015). Disparities in hospice care have grown for African Americans, American Indians, Alaska Natives, and Hispanics in the receipt of care inconsistent with their stated end of life wishes and with inadequate pain management (AHRQ, 2015). The cause of this widening is attributed to the improvements in quality experienced by the non-Hispanic White population have not extended uniformly to these other groups (AHRQ, 2015). The health of historically underrepresented groups has continued to fall behind the health of White Americans as shown in the differential rates of morbidity, mortality, and prevalence of chronic diseases among various racial and ethnic groups (AHRQ, 2012; AHRQ, 2015).

Health equity is the underlying principle in eliminating health disparities. Health equity is equated with social justice, whereas no one is denied the possibility to be healthy for belonging to a group that has historically been disadvantaged (Braveman, 2014). "Pursing health equity means striving for the highest possible standard of health for all people and giving special attention to the needs of those at greatest risk of poor health based on social conditions (Braveman, 2014, p. 1). Health disparities are the metric used to measure progress towards health equity (Braveman, 2014). Progress in health equity is achieved by selectively improving the health of those who are socially disadvantaged, not by worsening of the health of those advantaged groups (Braveman, 2014; Whitehead \& Dahlgren, 2006).

\section{Current and Projected US Demographics}

\section{Population Demographics}

There is indisputable evidence that health disparities related to race and ethnicity exist, yet at the same time, the United States is rapidly becoming a more diverse nation. It 
is projected that non-white racial and ethnic groups will constitute a majority of the American population later in this century (IOM, 2004). According to the US Census Bureau (2012), the Hispanic population is projected to more than double, from 53.3 million in 2012 to 128.8 million by 2060 resulting in nearly one in three U. S. residents being Hispanic (US Census Bureau, 2012). The African American population is expected to increase from 41.2 million to 61.8 million and the Asian population is projected to more than double, from 15.9 million to 34.4 million over the same time (US Census Bureau, 2012). Among the remaining racial groups, American Indians and Alaska Natives are projected to increase by more than half, from 3.9 million in 2012 to 6.3 million by 2060 (US Census Bureau, 2012). The number of people who identify themselves as being of two or more races is projected to more than triple, from 7.5 million to 26.7 million over the same period (US Census Bureau, 2012). The population of non-Hispanic White is projected to peak in 2024, at 199.6 million, up from 197.8 million in 2012. However, its population is projected to slowly decrease, falling by nearly 20.6 million from 2024 to 2060 (US Census Bureau, 2012). People of color, now 37 percent of the US population, are projected to comprise the majority, 57 percent, by 2043 (US Census Bureau, 2012).

\section{Health Professions Workforce Demographics}

Racial and ethnic diversity within the health professions is far different from the representation of the US population. The overwhelming majority of the US health care workforce is non-Hispanic White and comprise $72.2 \%$ of physicians, $73.7 \%$ of pharmacists, $80.5 \%$ of dentists, $81.6 \%$ of physician assistants, and $87.2 \%$ of occupational therapists (US Department of Health and Human Services, Health Resources Administration, National Center for Health Workforce Analysis, 2014). The US nursing 
workforce is not much different. According to a 2013 survey conducted by the National Council of State Boards of Nursing (NCSBN) and The Forum of State Nursing Workforce Centers, $81 \%$ of registered nurses are White/Caucasian with only $19 \%$ of nurses from other racial and ethnic backgrounds (NCSBN, 2015). These numbers represent a slight increase in diversity from the 2008 National Sample Survey conducted by HRSA (2010) which reported $17 \%$ of the $\mathrm{RN}$ workforce was of a race and ethnicity other than White, non-Hispanic. An examination of the numbers of graduates completing basic nursing education programs revealed that between 2005 and 2008, 22.5\% of the graduates were non-White compared with 12\% between 1981 and1985 (Gillis, Powell, \& Carter, 2010). Although there has been a slight increase in diversity within the nursing profession, it has not kept pace with the rapid change in US population demographics. Hispanic and African American people make up 3\% and 6\% of the registered nurse workforce, compared to $17.6 \%$ and $13.3 \%$ of the U.S population (NCSBN, 2013).

\section{Health Care Workforce Diversity Strategy}

\section{HRSA Diversity Conceptual Model}

A strategy commonly referred to in the literature suggests health disparities could be influenced by changing the ethnic and racial profile of the health professions workforce to better approximate that of the US population (IOM, 2003, IOM, 2004; HRSA, 2006; The Sullivan Commission, 2004). Two landmark reports, The Sullivan Commission's, Missing Persons: Minorities in the Health Professions (2004), and the Institute of Medicine, In the Nation's Compelling Interest: Ensuring Diversity in the Health-Care Workforce, (2004) first outlined the rationale for this strategy and brought national attention to it. HRSA later (2006) constructed a conceptual model to 
demonstrate the "chain of logic" from which this strategy was derived based on the limited research at the time. The model illustrates four separate pathways by which a racially and ethnically diverse health care provider workforce may improve health outcomes. (Figure 1).

Figure 1. HRSA Diversity Conceptual Model

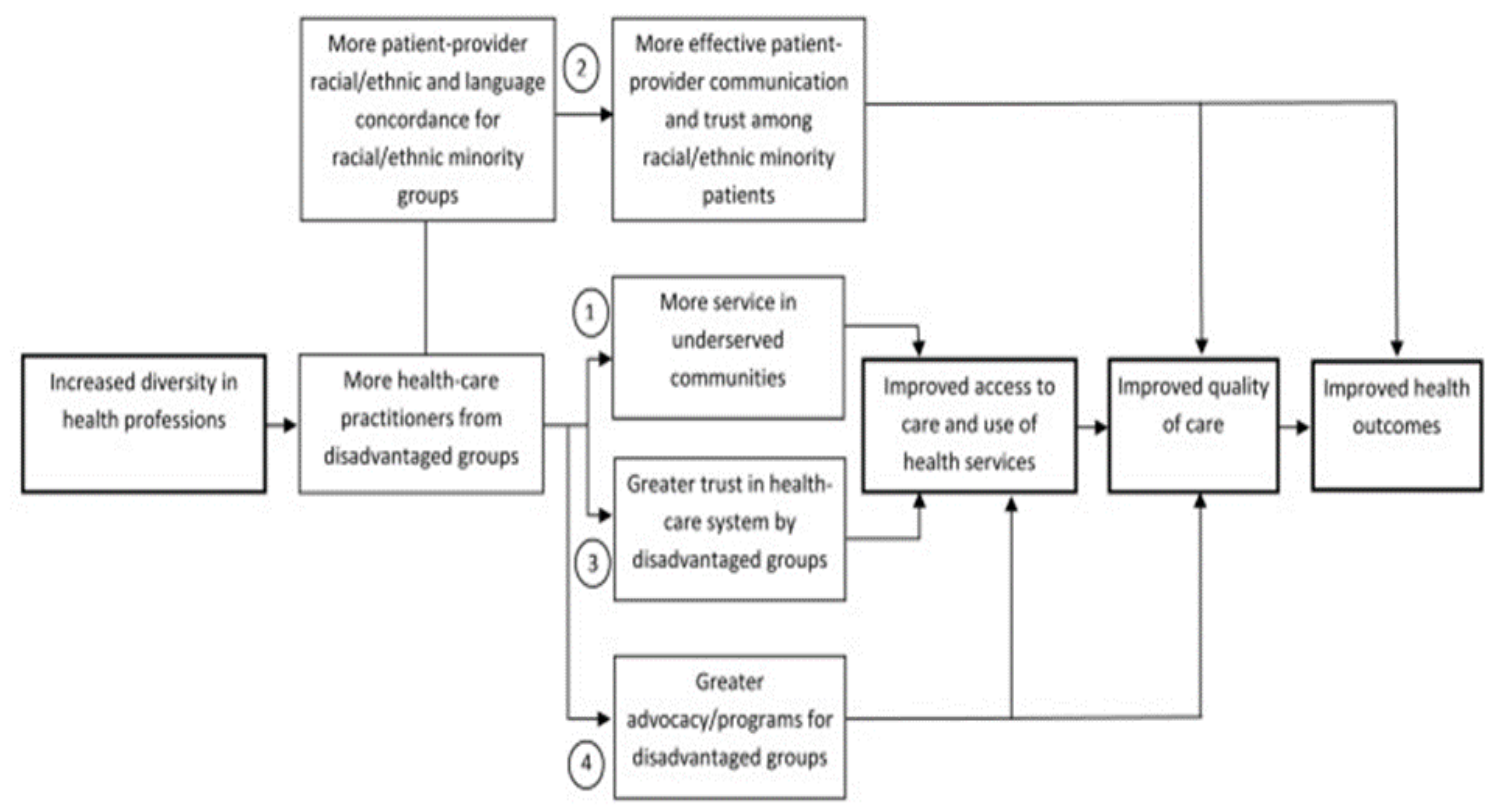

The first pathway describes an influence on service patterns whereas greater diversity among health professionals may lead to greater diversity in geographic locations where health professionals practice and in the populations they serve (HRSA, 2006). Specifically, health professionals from racial and ethnic minority backgrounds and socioeconomic disadvantaged backgrounds may be more likely than others to serve racial and ethnic minority and socioeconomically disadvantaged population groups (HRSA, 2006). This would improve access to health care services and ultimately lead to improved health outcomes (HRSA, 2006).

The second pathway describes that racial, ethnic, and language concordance 
between healthcare provider and patient may improve communication, comfort level, and trust thereby increasing patient decision-making and participation in their care (HRSA, 2006). This ultimately may increase adherence to treatment regimens resulting in improved health outcomes (HRSA, 2006).

The third pathway describes that more health professionals from disadvantaged backgrounds may improve trust in the health care delivery system for disadvantaged and minority populations. Improved trust may increase utilization of services and result in improved health outcomes (HRSA, 2006). "Racial and ethnic minority patients, in particular, may distrust health systems and institutions that are managed by predominately White health professionals, due to historical segregation and discrimination," (HRSA, 2006, p7).

The fourth pathway describes an influence on advocacy for broader priorities of the health care delivery system. The model postulates that health professionals from socioeconomic disadvantaged and minority backgrounds maybe greater advocates for policies, programs, allocation of resources, and research initiatives aimed at improving health outcomes for underserved and vulnerable populations (HRSA, 2006).

\section{Empirical Relevance}

There is evidence in the literature to support much of this model. Several studies have documented evidence that minority physicians disproportionality practice in underserved communities and provide care to low income and minority patients more so than non-minority physicians (Bach, Pham, Schrag, Tate, \& Hargraves, 2004; Gray \& Stoddard, 1997; Komaromy et al., 1996; Marrast, Zallman, \& Woolhandler, 2014; Moy \& Bartman, 1995; Stinson \& Thurston, 2002). Race was found to be a stronger predictor of 
serving the underserved more so than socioeconomic background or provider financial incentives (Brotherton, Stoddard, \& Tang, 2000; Rabinowitz, Diamond, \& Gayle, 2000).

Studies have also linked patient-provider race, ethnic, and language concordance with greater patient satisfaction (LaVeist \& Nuru-Jeter, 2002; LaVeist \& Carroll, 2002; Saha, Komaromy, Koepell, \& Bindman, 1999), improved communication (Cooper et al., 2003; The Sullivan Commission, 2004), shared decision making (Cooper-Patrick, Gallo, \& Gonzalez, 1999; Cooper et al., 2003), and increased patient adherence to treatment (Cooper et al., 2003; Perez-Stable, Napoles-Springer, \& Miramontes, 1997). Parker et al. (2017) found that glycemic control improved for diabetic Latinos when they switched from language-discordant physicians to language-concordant physicians. Furthermore, racial, and ethnic concordance was also associated with preferred choice in provider (Saha et al., 1999) and with improved patient trust in the health care delivery system (Sohler, Fitzpatrick, Lindsay, Anastos, \& Cunningham; 2007). However, no studies were found that directly linked greater advocacy of programs and initiatives for disadvantaged and minority population groups by minority health care providers.

Other researchers have provided rationale for increasing workforce diversity. Cohen et al., (2002) argued that a diverse health care provider workforce would lead to more culturally competent care. They defined cultural competence as having the knowledge, skills, attitudes, and behavior required to provide optimal health care services to persons from a wide range of cultural and ethnic backgrounds (Cohen et al., 2002). They explained that different belief systems, cultural traditions, ethnic origins, family structures and a multitude of other culturally determined factors influence the way people experience illness, adhere to medical advice, and respond to treatment (Cohen et al., 
2002). "Physicians and other health care professionals who are unmindful of the potential impact of language barriers, various religious taboos, unconventional explanatory models of disease, or traditional "alternative" remedies are not likely to provide their patients with optimally effective care," (Cohen et al., 2002, p. 92).

\section{Nursing Workforce Diversity}

Much of the research on racial and ethnic diversity of the health professions has been derived from the study of physicians. However, nursing leaders at all levels, national nursing organizations, government entities, and many other stake holders have made increasing the diversity in race and ethnicity of the nursing workforce to mirror that of population demographics a national priority. "The nursing profession, by virtue of its numbers and adaptive capacity, has the potential to effect wide reaching changes in the health care system;” (IOM, 2011, p. 2). Nurses comprise the largest sector of the healthcare workforce and they practice at all levels and across settings within health care (IOM, 2001). "Nursing practice covers a broad continuum from health promotion, to disease prevention, to coordination of care, to cure-when possible, to palliative care-when cure is not possible" (IOM, 2011; p4). In many instances, nurses are the patient's first point of contact within the health care system and nurses spend more time assessing and managing patients than other healthcare providers (Ballantyne, 2008). There is also a growing consensus that the current gap in demand and supply of primary care providers could be readily filled by advanced practice nurses and registered nurses in expanded roles (Bodenheimer \& Bauer, 2016).

It is recognized in the literature that there is very little empirical evidence linking nursing workforce diversity with reduction or elimination of health disparities (Gillis, 
Powell, \& Carter, 2010). Villarruel (2011) argued; "the profession must move beyond demonstrating the impact of a small proportion of the nursing profession in improving health outcomes for disparate populations to a focus on what the profession has and can do as a whole in ensuring equity and social justice to populations that have been historically disenfranchised, segregated, and denied opportunities for health and education in a democratic society" (p. 4). Further, the widening of opportunities available in the nursing profession, also serve as a means toward upwards social mobility for individuals from disadvantaged backgrounds (Bovbjerg \& McDonald, 2014).

\section{Nursing Pipeline Initiatives}

Schools of nursing recognize the need to recruit, retain, and graduate nursing students from diverse backgrounds. Although the number of minority nursing students in baccalaureate nursing programs have increased over the past several years, comprising up to $25 \%$ of the student body, minority students also experience high attrition rates (American Association of Colleges of Nursing [AACN], 2015; McLain et al., 2017). Contributing to attrition are financial constraints, problems related to academic and social adjustments, low high school achievement, lack of academic preparation, linguistic differences, lack of role models, lack of family support, encounters with discrimination and racism, and family care responsibilities requiring students to work more and study less (Amaro, Abrian-Yago, \& Yoder, 2006; Childs, Jones, Nugent, \& Cook, 2004; Loftin, Newman, Dumas, Gilden, \& Bond, 2012; Loftus \& Duty, 2010; McLain et al., 2017). Nursing programs have developed a variety of targeted programs to increase recruitment, retention, and graduation rates of minority nursing students. These programs have ranged from mere exposure to nursing as a career to programs that support student achievement 
at every post-secondary level (Carthon et al., 2014). Dapremont (2013) evaluated peerreviewed articles published between 2003-2010 and identified several key characteristics of successful recruitment and retention strategies. They included; academic and peer support before admission and during nursing school, community partnerships, mentoring, visible minority faculty, and social and financial support (Dapremont, 2013). Loftin et al. (2012) reported similar findings in their integrative review of interventions used by nursing programs to increase graduation rates of minority students in prelicensure nursing programs. They found that recruitment efforts aimed at high school students, access to technology, and cultural awareness and sensitivity of faculty, were as important (Loftin et al., 2012). Additional studies found that peer and faculty tutoring and formal mentors that followed students through school and post-graduation also enhanced retention and success in graduation rates (Banister, Bowen-Brady, \& Winfrey, 2014; Degazon \& Mancha, 2012).

To assist schools of nursing in their recruitment and retention efforts of underrepresented nursing students, the US government and several national philanthropic organizations have provided funding in the way of minority student and faculty scholarships, loan repayment programs, and programmatic grants. Nursing Workforce Diversity Grants, funded under Title VIII of the Public Health Service Act, have funded initiatives that not only addressed the financial and academic barriers identified in the literature that contribute to the lack of success in recruitment and program completion, but also included initiatives that focused on the social disparities experienced by these population groups. Robert Wood Johnson Foundation in concert with AARP, have provided funding through State Implementation Program (SIP) grants for state nursing 
diversity initiatives, through the work of the "Campaign for Action", a national collation of stake holders mobilized to implement recommendations from the Institute of Medicine's Future of Nursing report (IOM, 2011). Lastly, the passage of the Affordable Care Act (ACA, 2010) reauthorized and expanded the Title VIII Nursing Workforce Development programs adding additional money and focus to increasing nursing workforce diversity. Although there has been an increase in the number of minority nursing graduates since 2008 (AACN, 2015), most likely due to the success of these national programs, the relatively small number of student participants in each program have had minimal impact in increasing the overall numbers of diverse nurses in the workforce (Carthon et al., 2014).

\section{Pre-Collegiate Barriers}

There is consensus in the literature that the greatest barrier to increased diversity in all health professions starts at the beginning of the education pipeline in public primary and secondary schools where there is a significant achievement gap for many minority and disadvantaged students (The Sullivan Commission, 2004; Villarreal et al., 2001, NEC, 2016). On average, when compared to white students, disadvantaged students of color receive a K-12 education of measurable lower quality, attend poorly funded schools, have more inexperienced teachers and more math teachers who did not met the required certifications to teach the subject, and have limited access to advanced placement courses (The Sullivan Commission, 2004; Institute of Medicine, 2004; NCES, 2010). Minority and low income students are also disproportionality tracked into lower level courses and sequences, especially in mathematics, based on cultural stereotypes or through other mechanisms of inequity (Archbald \& Farley-Ripple, 2012). These lower level courses 
and sequences often do not meet post-secondary admission requirements thus preventing pursuit of a college degree (Villarruel, Canales, \& Torres, 2001; Archbald \& FarleyRipple, 2012). Students of color and/or low income are also more likely to receive poor high school career counseling (Manney \& Fonza-Thomason, 2010) and consistent messages from high school teachers and guidance counselors that college is not a realistic option (Villarruel, Canales, \& Torres, 2001). Latino cultures, while diverse, generally place more faith in teachers as experts in education and consequently are less likely than other parents to challenge teachers' education decisions and perspectives (Smith, Stern, \& Shatrova, 2008). This is especially prevalent when there are issues with English language fluency and immigration status (Moller et al., 2015). Cooper (2014) found that minority students were less likely to enroll in a health science major because they were less likely to be exposed to situations that traditionally encourage student aspiration, interest, and achievement in college. When compared to White and Hispanic students, African American students have the highest participation rates in career technical and vocational education tracks, which are often less demanding, thus contributing to the underpreparedness of these students for matriculation into higher education (Lewis, 2007)

Academic performance measures reflect these inequities. Significant achievement gaps exist in mathematics, science, and reading scores for American Indian/Alaska Native, Hispanic and Black students as compared to Asian/Pacific Islander and White students (NCES, 2016). Black students experience the biggest gap, scoring the lowest in all three subject areas (NCES, 2016). Public high school graduation rates are lower for American Indian/Alaska Native, (70\%), Black (73\%) and Hispanic (76\%) students compared to White (87\%) and Asian Asian/Pacific Islander (89\%) students (NCES, 
2016). College enrollment rates for White 18 - to 24 -year-olds are higher (42\%) than for their Black and Hispanic peers (34\%) (NCES, 2016).

\section{Pre-College Social Cognitive Factors}

Instructional opportunities rather than academic potential has been suggested in the literature as the primary cause for the lack of post-secondary success for underrepresented students in college programs and entry into professions such as nursing and health care (Moller et al., 2015). Several scholars have called upon the investigation of other strategies to support a more expanded pool of students beyond the focus of achievement, by paying attention to the influence of social relationships, attitudes, interests, self-efficacy beliefs, expectations, and self-regulatory abilities (Crede \& Kuncel, 2008; Ing \& Nyland-Gibson, 2013; Louis \& Mistel, 2012). Studies have shown that high school students' self-efficacy and teacher and parental expectations were significant factors that impact initial post -secondary enrollment, academic persistence, and degree completion (Adelman, 2006; Engberg \& Wolniak, 2010; Fouad \& Santana, 2017). Other researchers have found that social support and self-beliefs were powerful predictors of academic persistence in college for undergraduate Latina and Latino students (Bordes-Edgar, Arrendond, Kurpius, \& Rund, 2011; Gloria, Castellanos, Lopez, \& Rosales, 2005). Ojeda \& Flores (2011) found a significant direct path; from college self-efficacy to academic goal progress, academic satisfaction, and college expectations for Mexican American college students. Self-efficacy was found to be particularly important in first generation college students and was strongly related to college GPA (Major, 2009). Sommerfeld (2016) found that personal, peer, and parental educational expectations were predictive of educational outcomes, even when controlling for student 
background characteristics and high school achievement level. Conklin and Daily (1981), found that high school students who reported consistent parental encouragement from ninth grade through $12^{\text {th }}$ grade was predictive of entry into a four-year college. Several studies found a direct relationship between parent encouragement in mathematics and science courses with student's interest and self-efficacy in these subjects (Ferry, Fouad, \& Smith, 2000; Fouad \& Santana, 2017).

Researchers have found that these social constructs also greatly influence career choice and development. As early as middle school, students begin investigating career choices (Cohen, Palumbo, Rambur, \& Mongeon, 2004, Hoke, 2006; Knight, Abdallah, Findeisen, Devereaux-Meillo, \& Dowling, 2011), and are greatly influenced in these choices by teachers, guidance counselors, parents, and peers (Cabrera \& La Nasa, 2000; Manney \& Fonza-Thomason, 2010; Villarruel, Canales, \& Torres, 2001). Lee (1984) proposed that parental influences on African American youth's career development may be stronger than those of their white counterparts. Fuchs \& Miller (2012) found that overt parent encouragement of college attendance and encouragement of mathematics and science were substantially more important factors than level of parent educational attainment for students' pursuit of careers in medicine and health.

\section{Theoretical Framework}

Social Cognitive Career Theory (SCCT) was the theoretical framework used in this study. It describes the process of career development through the lifespan; at the time people form interests, make choices, achieve varying levels of success in educational and occupational pursuits, achieve work satisfaction, and navigate and adapt to situations in pursuit or within their chosen field (Lent \& Brown, 2006, 2013; Lent, Hackett, \& Brown, 
1994, 2000). The SCCT framework consists of five interlocking models; career interest, career choice; performance, work satisfaction, and career self-management. For the purpose and scope of this study, variables from the Career Choice model were used. It was the ideal model to look at social cognitive variables that may influence nursing career interest, choice of college major, and academic achievement towards nursing degree completion. It also considered gender, culture, and other aspects of human diversity within the context of this career development.

The first three models have been well established in the career research literature, whereas the last two models are more recent and gaining attention and interest. This section will provide a review of the evolution of SCCT. Next, a detailed review of the first three models is presented, since its relevance and understanding is central to this study. Finally, an overview of the last two models is given.

The foundational concepts of SCCT (Lent, Hackett, \& Brown, 1994) were derived largely from Bandura's social learning (Bandura,1971), self-efficacy (Bandura, 1977) and social cognitive theories (Bandura,1986).

\section{Social Learning Theory}

Bandura's (1971) social learning theory, expanded beyond traditional behaviorist theories and provided a unique perspective to explain human behavior. Behaviorists hypothesized that human behavior was a result of external and environment forces that had received a positive or negative reinforcement. Bandura (1971) asserted that "man's superior cognitive capacity was another factor that determined not only how he would be affected by his experiences, but the future directions his actions may take" (p. 2). SLT asserted that internal cognitive introspection of one's experiences and observations 
determined one's behavior. Cognition, environment, and behavior all mutually influenced each other in which Badura coined reciprocal determinism (Bandura, 1971).

\section{Self-Efficacy Theory}

As a major development to SLT, Bandura described self-efficacy as a major mediator in behavior and behavior change (Bandura, 1977, 1986). Bandura (1986) defined self-efficacy as "people's judgments of their capabilities to organize and execute courses of action required to attain designated types of performance" (p. 391). He postulated that if one believed he or she was capable of conducting a certain task (had high self -efficacy beliefs) then this belief would influence the persistence of behavior even when disconfirming or dissuading experiences were confronted (Betz \& Hackett, 1981). Conversely, if one believed that they would not be successful at completing a specific task, then one would not even attempt the task. Bandura described self-efficacy beliefs as constituting the most central and pervasive mechanism of personal agency (Bandura,1989).

Self-efficacy beliefs are learned and modified through four types of information (Figure 2); performance accomplishments, vicarious learning, verbal persuasion, and physiological state (Bandura, 1977). Performance accomplishments provide information from the previous performance of the desired behavior. Successful mastery increases self-efficacy beliefs, whereas previous failures lower them. Vicarious experiences involve role models and learning by observing others. Seeing people succeed by sustained effort raises observers' beliefs that they too possess the capabilities to master comparable activities, however observations of failure, despite high effort, lowers efficacy (Bandura, 1977). Verbal persuasion involves being encouraged by others that they possess the 
capabilities to master given activities. Discouragement or dissuasion by others to engage in an activity, negatively affects efficacy beliefs. Lastly, physiological and affective states, like anxiety, also inform self-efficacy. High levels of anxiety, clearly undermine self-efficacy, although moderate levels maybe facilitating (Bandura, 1986). Bandura theorized that performance accomplishments were the strongest sources of information for self-efficacy judgements (Bandura, 1986). However, vicarious learning experiences and verbal encouragement, especially from culturally similar coping role models, can promote stronger efficacy while inhibiting anxiety and negative emotional arousal (Byars \& Hackett, 1998).

Figure 2. Self-Efficacy Model

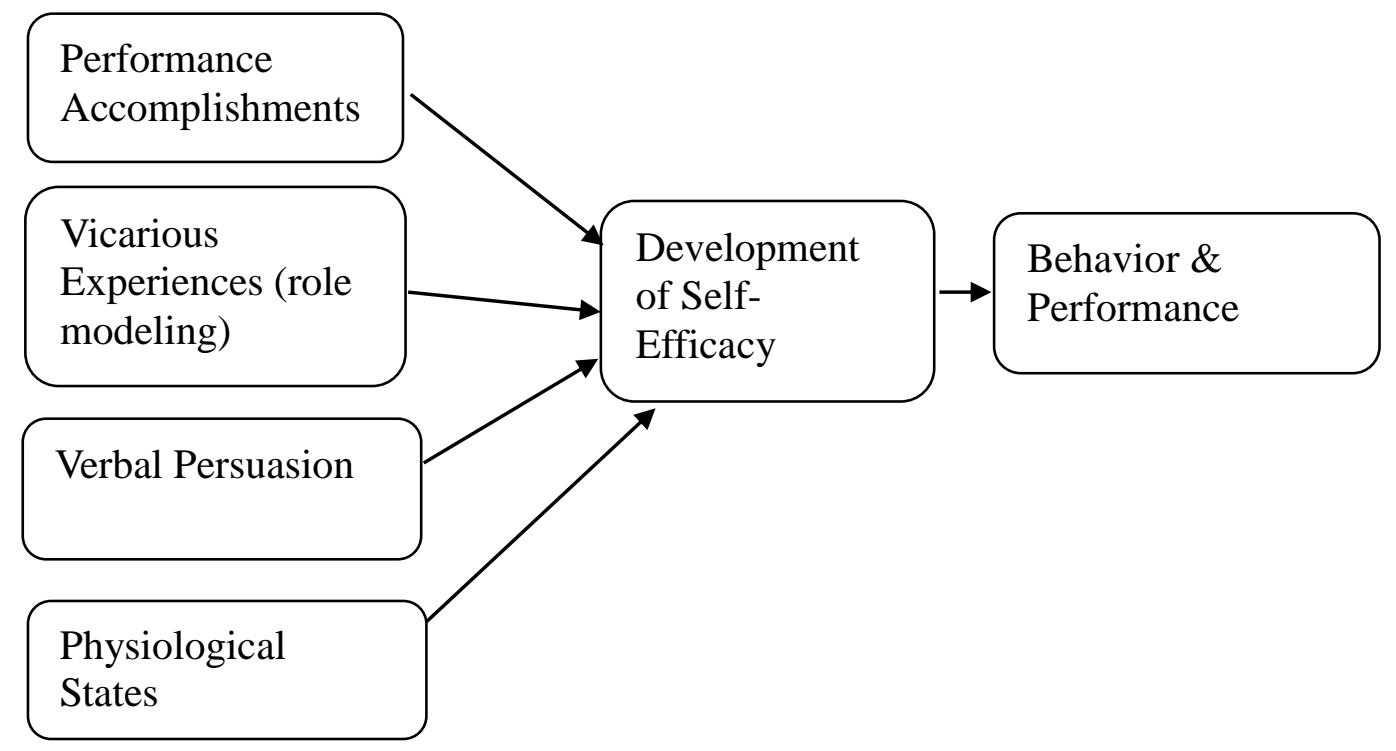

\section{Social Cognitive Theory}

Badura expanded upon his earlier theoretical thinking creating social cognitive theory (1986). SCT postulates a triadic reciprocal determinism model in which personal attributes, external environmental factors, and overt behavior all operate as interacting determinants that influence each other bidirectionally (Bandura, 1986). The uniqueness 
of the model is that behavior is considered not just a byproduct of the interaction of person and environment but functions as an interactive co-determinant of this transaction (Bandura, 1986). Through this view, overt actions (behavior) influence situations that in turn affect thoughts, affect, and subsequent behavior (Bandura, 1986).

Personal attributes defined within the triadic casual model, include social cognitive mechanisms of self-efficacy, outcome expectations, and goal setting. Bandura defined outcome expectations as personal beliefs about probable response outcomes (Bandura, 1986). "Whereas self-efficacy beliefs were concerned with one's response capabilities, (i.e. can I do this?) outcome expectations involved imagined consequences of performing particular behaviors (i.e. if I do this, what will happen?)," (Lent et al., 1994, p. 83). Outcomes expectations were derived from the same learning experiences that influenced self-efficacy; performance accomplishments, vicarious learning, verbal persuasion, and physiological state (Bandura, 1986). Bandura distinguished between several classes of outcomes expectations; physical (monetary), social (approval), and selfevaluative (self-satisfaction) outcomes (Bandura, 1986). Even when outcome expectations were perceived as resulting in a positive consequence, Bandura asserted that self-efficacy would serve as a more potent influencer (Bandura, 1986). However, Bandura (1986) also described situations where self-efficacy maybe high, yet the selfperceived expected outcome may not provide the monetary, social or self-satisfaction that was desired.

Bandura asserted that individuals were not just responders to internal and external factors, but had the ability to organize and guide their behavior sustaining it over long periods of time in the absence of external reinforcement through the process of goal 
setting (Bandura, 1986). He defined goal setting as the determination to engage in a particular activity to affect a particular outcome (Bandura, 1986). Goals operated principally through people's capacity to envision desired future outcomes and to regulate their own behavior and performance (Lent et al., 1994). Bandura described a dynamic reciprocal relationship among self-efficacy, outcome expectations and goal setting in this framework (Bandura, 1986).

\section{Social Cognitive Career Theory Models}

Career researchers saw the applicability of Bandura's theoretical thinking as a major contributor to understanding career choice and development. Hackett and Betz (1981) were the first to apply Bandura's self-efficacy theory to understand vocational behavior and career development in women in general and women's under representation in scientific and technical careers in particular. Their research found that self-efficacy beliefs influenced educational and occupational choice, performance, and the persistence in implementing those choices (Betz \& Hackett, 2006). They also found that differential background experiences associated with gender role socialization lead to gender differences in self-efficacy and confidence with respect to specific domains of career behavior (Betz \& Hackett, 1981; Betz \& Hackett, 2006). Their empirical work inspired other vocational and career researchers to replicate their research in understanding career self-efficacy in women and for other specific groups of people deemed vulnerable including people of color (Byars \& Hackett, 1998, Gloria \& Hird, 1999).

SCCT was built primarily from this work (Betz \& Hackett, 1981; Hackett \& Betz, 1981; Betz \& Hackett, 2006). A central concept of SSCT is self-efficacy but is it also incorporates the essential variables of outcome expectations, goal setting, and the 
complex reciprocal linkages consistent with SCT (Lent, Brown, \& Hackett, 1994).

\section{Model of Career Interest}

In the first model (Figure 3), the variables of self-efficacy and outcome expectations are directly linked to developing career interests. A variety of experiences, both directly and vicariously, expose people to different careers leading them to develop self-efficacy beliefs about their own skills and outcomes expectations (Lent et al., 1994). Most people form interests in activities they view themselves to be efficacious and in which they anticipate positive outcomes (Lent et al., 1994). It is through these interests, that a person creates goals, and engages in activities and practices for goal attainment. The success or failure of these activities in goal attainment results in a revision of selfefficacy and outcome expectancy estimates (Lent et al., 1994). This process may continuously repeat itself over the lifespan, although by early adulthood this sequence generally stabilizes within a broad domain of an interest (Lent et al., 1994). This model is applicable at the beginning of the educational pipeline when career interests are just emerging as early as middle and high school.

Figure 3. SCCT Career Interests Model (Lent, Brown, and Hackett, 1994) 


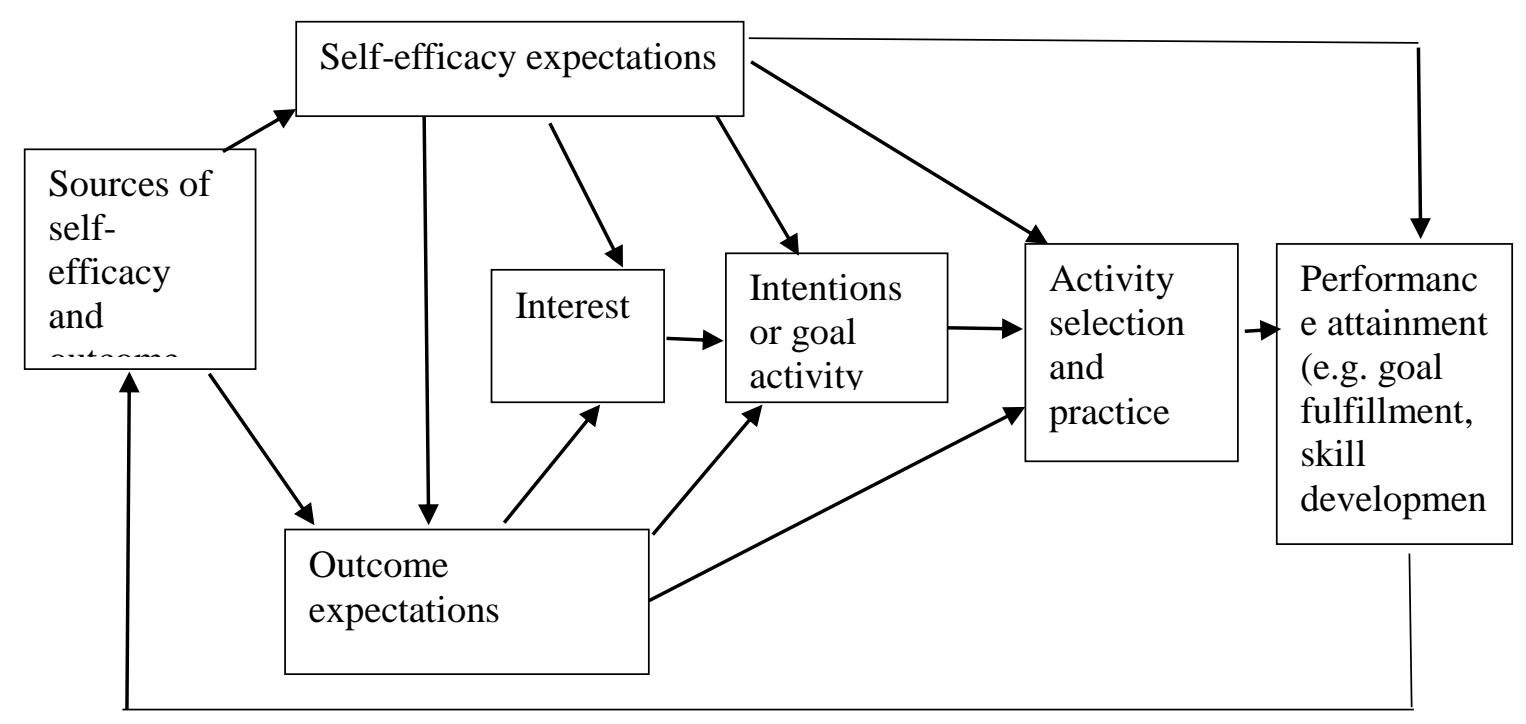

\section{Model of Career Choice}

The second model is a developmental extension of the career interest model, is the most complex, and identifies the variables that influence career choice behavior (Figure 4). The additional variables include person inputs, background contextual affordances, and contextual influences proximal to choice behavior (Lent et al., 1994). Person inputs include gender, race, ethnicity, health status, and predispositions. Background contextual affordances refer to a person's background, socioeconomic status, and family support. Both person inputs and distal contextual affordances directly influence learning experiences. Consistent with SCT, learning experiences are the primary source of selfefficacy and outcome expectations (Bandura, 1986). Contextual affordances proximal to choice behavior include external inputs for such as financial status or job opportunities that exist at the time career choices and goals are being made. Although the variables of 
self-efficacy and outcome expectations continue to be primary variables within this model, the resulting career choice maybe a compromise due to the influence of person input variables, background contextual affordances and contextual influences proximal to the choice behavior (Lent et al., 1994).

Figure 4. SCCT Career Choice Model (Lent, Brown, and Hackett,1994).

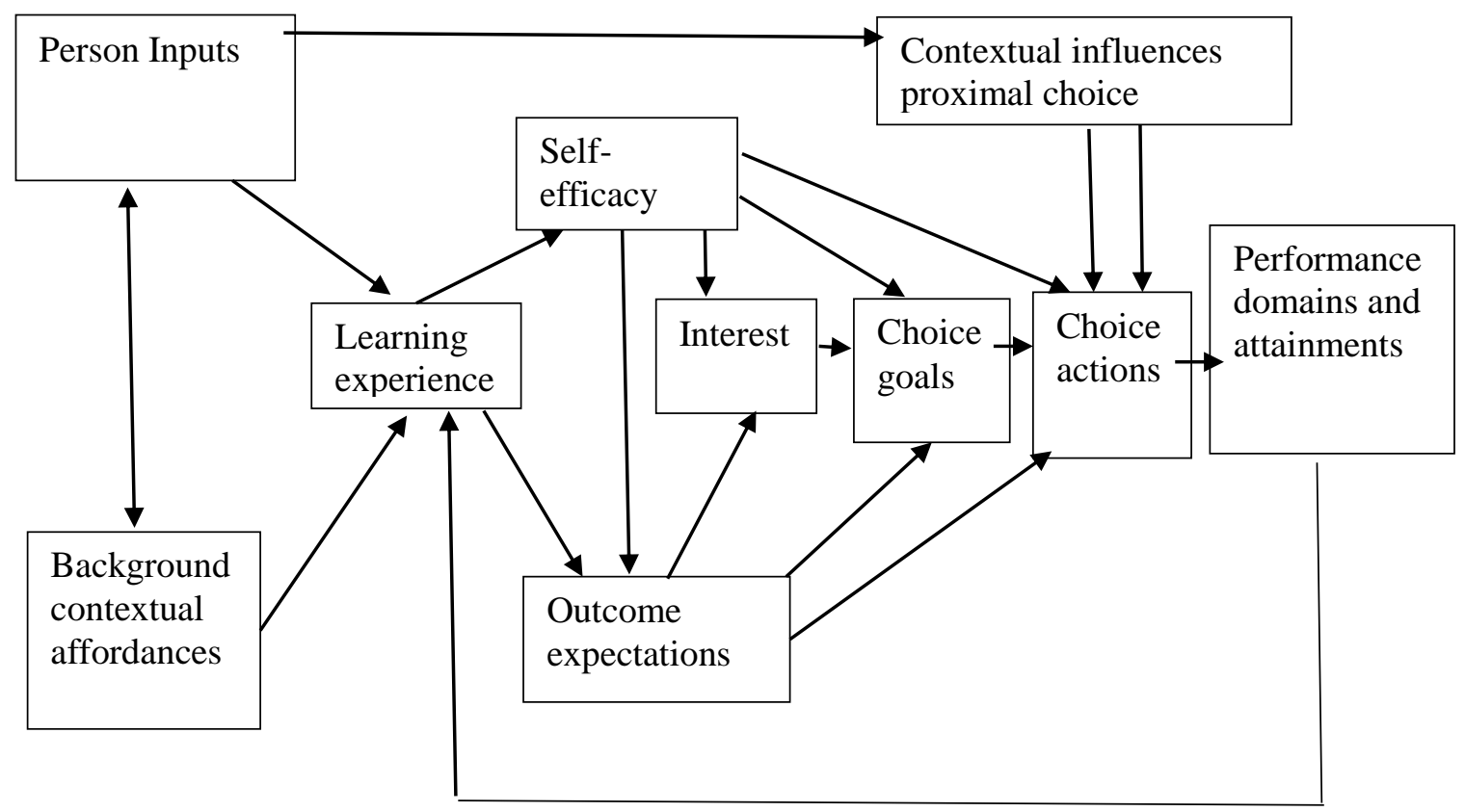

\section{Model of Career Performance}

The third model of performance (Figure 5) represents the active role of being in a career. It highlights the specific links between self-efficacy, outcome expectations, performance goals and performance attainment. Performance attainment level is defined broadly as level of accomplishments as well as behavioral persistence in career related pursuits (Lent et al., 1994). The model describes that past performance has a direct influence on self-efficacy and expected outcomes. Self-efficacy beliefs influence career performance both directly and indirectly through their effort on performance goals (Lent et al., 1994). Outcome expectations influence performance only indirectly though their 
effort on goals (Lent et al., 1994). This model does not include "interest" as an intermediate mechanism because it is viewed as more integral to choice of career and academic activities than to selection of performance goals within a career (Lent et al., 1994).

Figure 5. SCCT Career Performance Model (Lent, Brown, \& Hackett, 1994)

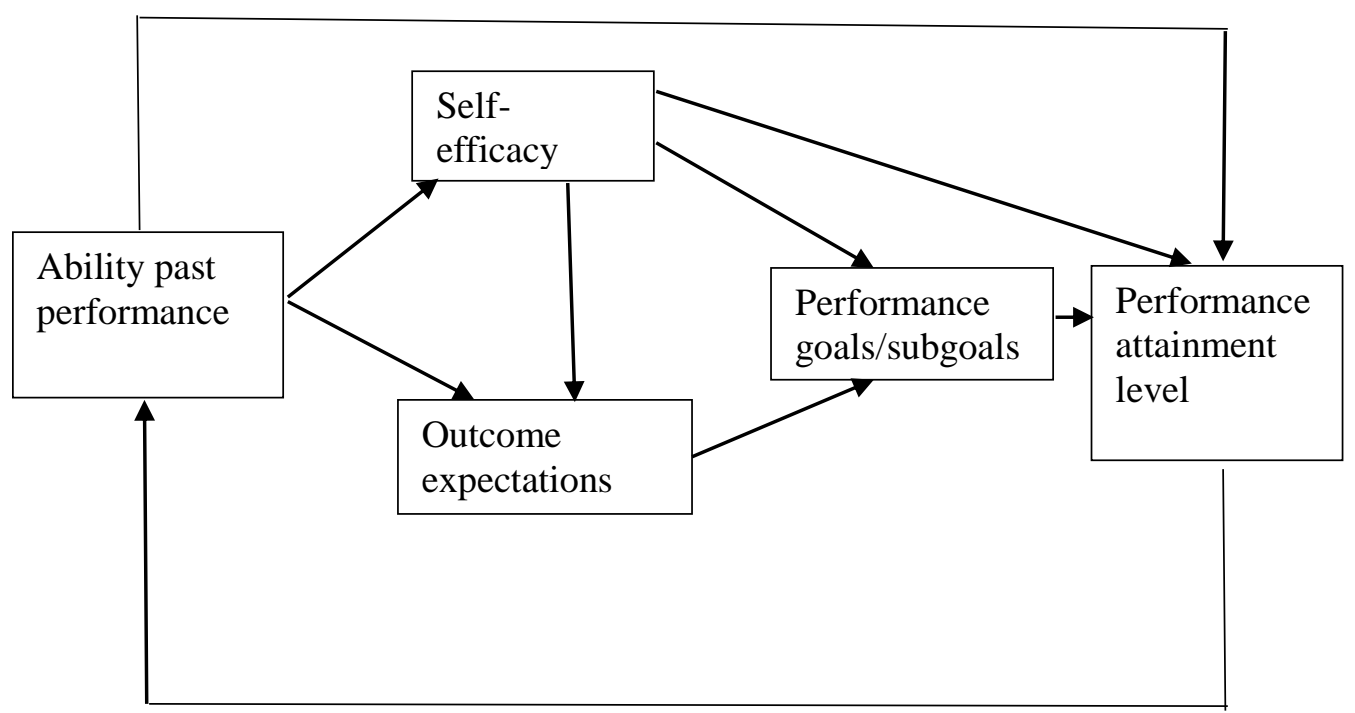

\section{Satisfaction and Career Self-Management Models}

The fourth model of SCCT is aimed at understanding satisfaction in vocational and education pursuits. Consistent with the foundational concepts of the previous models, the model of work satisfaction theorizes that core social cognitive variables (self-efficacy, goals) function jointly with personality/ affective traits and contextual variables which link to job satisfaction (Lent \& Brown, 2006).

The fifth model, career self-management, was developed because the existing model of interest, choice, performance and satisfaction do not address the vast changes that occur within the context of a career development such as economic uncertainties, global competition, technological advances, and decreased job security (Lent \& Brown, 
2013). The career self- management model is a framework to understand how people adapt and negotiate normal developmental tasks and less predictable events and crisis (i.e., job loss) over the lifespan. This model was created in response to the research on career adaptability and resilience (Lent \& Brown, 2013). It is intended to complement the existing models and offer a framework that extends beyond field and job selection alone. Lent and Brown (2013) explained that "the previous four models focus, metaphorically speaking, have been more on the destination than on the journey, that is where people end up, occupation wise, rather than on how they get there or how they manage new challenges once they arrive," (p. 557).

\section{SCCT Empirical Relevance}

The SCCT framework is well established in the career and vocation literature, especially in the investigation of adolescents' career interest and choice behavior precollege. Lee, Min, \& Mamerow (2015) used SCCT to investigate the influence of high school students' self-efficacy and expectations, as well as the expectation and encouragement they received from parents and teachers on their decision to major in, complete a degree, and pursue a career in a science, technology, engineering, mathematics, and medicine (STEMM). Their findings were that expectations played a significant role in student's choices in STEMM careers and teacher expectations were especially influential (Lee et al., 2015). Males were most affected by their teachers' expectations whereas females were most affected by their parents (Lee et al., 2015).

Several other studies have used the SCCT framework to understand social cognitive variables of middle school and high school students in relation to interest and pursuit of career in science, technology, engineering, and mathematics (STEM). These 
studies found that support from parents was directly related to math and science interest, and to self-efficacy and outcome expectations in a STEM field (Ferry et al., 2000; Turner, Steward, \& Lapan, 2004).

Navarro, Flores, \& Worthington (2007) investigated Mexican American middle school students' self-efficacy and outcome expectations toward math and science using a modified SCCT model. Results showed a positive relationship among academic accomplishments, self-efficacy, and math and science outcome expectations (Navarro et al., 2007).

Garriott et al. (2014) examined the role of parental support and learning experiences (i.e., performance accomplishments, verbal persuasion, vicarious influence, physiological arousal) in the development of math/science interests among high school students of color. Results found that parental support significantly predicted each learning experience variable, with the exception for physiological arousal (Garriott et al., 2014). Performance accomplishments were the only learning experience variable that predicted both math/science self-efficacy and math/science outcome expectations (Garriott et al., 2014). Self-efficacy significantly predicted interests, but did not predict outcome expectations, whereas outcome expectations did not predict interests (Garriott et al., 2014).

Ali and Menke (2013) used SCCT to investigate the career development of high school students in a rural community with a high percentage of Latino immigrants. The authors examined the relationships among variables of vocational self-efficacy, outcome expectations, perceptions of barriers, and career aspirations. Results were that Latino students reported a higher rate of perceived barriers and a higher vocation self-efficacy as 
compared to white students, however there was no difference in outcome expectation or career aspirations between the two groups. Contrary to the author's hypothesis, rural Latino students perceived that they were more likely to encounter barriers but felt more efficacious about achieving their career goals than the White students did (Ali \& Menke, 2013). In addition, Latino students shared similar outcome expectations and career aspirations of the White students. Although, the authors indicated a small sample size as a limitation to their study, they hypothesized a possible explanation was that school educators and counselors from this community may have been skilled in working with Latino students and knowable about promoting self-efficacy, career aspirations, and pursuit of higher education (Ali \& Menke, 2013).

The framework has also been used with research related to social class. Flores, Navarro, \& Ali (2017) conducted a review of 47 research articles published between 2006 and 2015 that employed social class variables to the SCCT framework. They found support that social class influences a range of SCCT variables and the SCCT model was useful in explaining the academic and career outcomes of people from poor and working class backgrounds (Flores et al., 2017). The authors called the findings important because "understanding factors that influence the intended and actual educational and occupation goals and persistence behaviors of people from low social class backgrounds is important in the development of prevention and intervention program targeted at enhancing and supporting their career goals," (Flores et al., 2017, p. 19).

The literature reveals the SCCT has demonstrated to be a useful framework for the investigation of social cogitative variables, especially in the pre-college years and with diverse populations including disadvantaged and unrepresented groups. In addition, 
several studies have explored career development through the SCCT lens for fields in science, technology, engineering, mathematics and medicine. Therefore, the applicability of this framework to this study was ideal for the investigation of career development in nursing and health care.

\section{Summary}

This chapter presented a review of the literature on the rationale for why diversity in the nursing and health care provider workforce is thought to be a critical strategy in the reduction and elimination of health disparities. This chapter also presented a review of the evidence on why the increase in diversity in the nursing and health professions workforce has been incremental and slow due to the barriers that students from diverse backgrounds face in pursuing a degree in nursing. A review of the recruitment and retention efforts that nursing programs have implemented to increase the number of underrepresented students was presented followed by the evidence that suggests initiatives may have greater impact if directed earlier in the educational pipeline prior to college admission. Lastly, this chapter presented an overview of the Social Cognitive Career Theory, the theoretical framework that guided this research study. 


\section{CHAPTER III:}

\section{METHODOLOGY}

This chapter presents the national data set used in this study, the Longitudinal Study of American Youth, the study design, the two-cohort sample, variable selections and coding, and the data analysis plan for the study. This chapter also describes the challenges posed by the secondary analysis of an established data set.

\section{Longitudinal Study of American Youth}

The research study has used a longitudinal design of a national study known as the Longitudinal Study of American Youth (LSAY; Miller, 2014). This is a publicly accessible data set through the Inter-University Consortium for Political and Social Research (ICSPR) at the University of Michigan. The ICSPR maintains and provides access to a vast archive of social science data for research and instruction. (https://www.icpsr.umich.edu).

The LSAY is a 20-year national longitudinal study of middle school and high school students funded by the National Science Foundation (NSF). The LSAY was designed to examine the development of; (a) student attitudes toward achievement in science and mathematics; (b) student interests in and plans for a career in science, mathematics, or engineering, during middle school, high school, and the first four years post-high school and; (c) to estimate the relative influence of parents, home, teachers, school, peers, media, and selected informal learning experiences on these developmental patterns (Miller, 1986). The LSAY provides the longest available longitudinal record of the impact of education and schooling on young adult career outcomes (Miller, 2014).

The LSAY began in 1987 with two cohorts totaling 5,945 students; 3,026 males 
(50.9\%) and 2,919 females (49.1\%). Cohort One consisted of 2,892 tenth grade students in public high schools throughout the United States who were followed for seven years, ending four years after high school (Miller, 2014). Cohort Two consisted of 3,116 seventh grade students in public schools that served as feeder schools to the same high schools in which the older cohort was enrolled and were followed seven years, ending one year after high school (Miller, 2014). In 2007, data collection resumed on both cohorts, then aged 33 to 37 years old. The focus of this wave of data collection was educational and occupational outcomes. Most of the participants in the two original cohorts were contacted to participate. Over 4000 adults participated in the subsequent data collection, resulting in a $78 \%$ response rate (Miller, 2014). The later data collection cycle continued through 2011.

\section{LSAY Sample}

LSAY students were recruited through a two-stage probability sampling scheme. Stage I involved the selection of schools through a 12 strata classification by region (Northeast, Midwest, South, and West) and community type (urban, suburban, and rural). A random sample of high schools were drawn in each stratum, with 54 schools consenting to participate. The middle schools that served as feeder schools to the high schools were then selected for inclusion. Many of the sampled high schools received students from several middle schools, and in those cases a selection had to occur (Miller, 2014). "The selection procedure involved calculating the proportion of students in the high school who came from each feeder school and then randomly selecting one feeder school, where the probability of selection was proportional to the feeder's contribution to the high school's enrollment," (Miller, 2014, p.6). Two high schools and their feeder 
middle schools were later dropped prior to data collection for non-compliance.

Stage II involved the random selection of age-appropriate students from each school. Each school provided the LSAY a complete student roster for the seventh and tenth grade cohorts. Students were randomly selected from the lists and asked to participate until the target sample of 60 students at each school, large enough to compute school effects, was achieved. In schools with fewer than 60 students, all students participated. Once the student sample was obtained, a unique identification number was assigned to each student for tracking. The sample design used for the LSAY was complex and involved a stratified cluster sampling and unequal probabilities of selection. The authors noted that, "the decision to select samples of equal size from each school (where schools did not have the same enrollment counts) led to varying probabilities of selection for different students, thus the need for weights in analysis to make unbiased, representative population inferences," (West, 2014, p. 75). Weighting was also required to account for any student attrition from the selected schools. The complete details of the LSAY sample selection and procedures can be accessed at www.lsay.org.

\section{LSAY Procedures}

The LSAY collected data from the student cohorts through questionnaires, achievement tests, and telephone surveys. Student attitudinal questionnaires, created by the LSAY staff, were administered during the fall and spring of each academic year throughout high school. Students who missed or did not complete a questionnaire in the academic year were contacted the summer immediately following, and interviewed by phone. Student responses to questions about occupational choice were coded using the 1970 Occupational Classification system devised by the US Census Bureau. 
Occupational questionnaires allowed for open ended responses therefore requiring LSAY staff to select the most appropriate code. Questions regarding student's college major, also open ended, required staff to select a code using a college major dictionary file created by the LSAY staff. When exact codes were not available, the majors were coded into the closest corresponding category (Miller, 2014). After high school completion, all data collection was conducted by phone interviews including responses to college major and occupation in 2007.

Parents were interviewed by phone annually. Most interview questions were close-ended, except for responses to parent and spouse's occupation. The same 1970 Occupational Classification System was used to code these responses as was used for the student responses to occupation. However, parents and spouse occupations were further coded to represent employment in a STEMM (science, technology, engineering, mathematics, medicine) profession or in a STEMM support position. Miller and Solberg (2012) created a definition to differentiate between professional and support careers in these fields. They defined STEMM professional as one with graduate education, substantial independence in their work, and responsibility for the supervision of other technical occupations. They defined the latter group as workers with scientific or technical education but who generally worked under the supervision of a professional and who rarely defined the tasks that they perform (Miller \& Solberg, 2014). Since its inception in 1987, the LSAY's main interest was tracing the entrance of participants into the scientific workforce and thus included a question for parents about their employment in a STEMM field. The LSAY tested student achievement in mathematics and science every fall through high school. The LSAY tests comprised of items developed by the 
National Assessment of Educational Progress (NAEP, 1986). In 1992, the last year of test administration, the tests were updated to raise achievement ceilings for both mathematics and science (Miller, 2014). In 1996 the achievement scores were recalibrated to put the results for the two cohorts on the same metric for the merged cohort file (Miller, 2014).

Reading comprehension tests were administered to both cohorts in the spring of their $12^{\text {th }}$ grade. Tests items were developed by the Educational Testing Service for the US Department of Education surveys; High School and Beyond and the National Longitudinal Study of 1992 (https://nces.ed.gov/statprog/handbook/pdf/hsb.pdf). Alpha reliabilities of the reading test scale, met assumptions at .86. A detailed summary of LSAY data collection activities can be found at http://www.lsay.org.

\section{Present Study}

The sample for the present study was derived from the merged Cohort sample file of the LSAY (included both Cohort One and Cohort Two). Following the three study aims, the sample inclusion criterion was that participants must have completed the 2007 questionnaire reporting their current occupation. This resulted in a sample size of 4009 participants from a total of 5,945 (67\%) of the original sample. Therefore, the present study sample was a national representative sample of age-appropriate high school students who participated in the longitudinal LSAY study over 12 repeated data collection waves from ages 13 through 37 . Due to the sample scheme, the appropriate weightings were applied in the analysis as recommended (Miller, 2014). The present study did not require Institutional Review Board review by the University of Rhode Island (Appendix A). 


\section{Variable Selection}

Social Cognitive Career Theory and specifically, the Career Choice model (Lent, et al., 1994) provided guidance for the selection of variables. Although the LSAY was initiated prior to publication of the SCCT model, a substantial number of variables collected measure equivalent or similar constructs (Solberg, Kimmel, \& Miller, 2012). The conceptual foundation of the LSAY was derived from social psychology and Bandura's learning theories (Solberg et al., 2012).

As previously stated, the major constructs of SCCT include the influence of person inputs, background contextual affordances, self-efficacy beliefs, and expected outcomes on career interest development, goals, actions to achieve career goals, and eventually performance attainment. Proximal to choice actions are external contextual influences. The focus of this study was high school influences on three points of the career continuum. Therefore, the construct of contextual influences proximal to choice behavior was not included. The highlighted boxes in Figure 6 indicate the SCCT framework that was measured in this study. 
Figure 6. Study Constructs of SCCT Career Choice Model

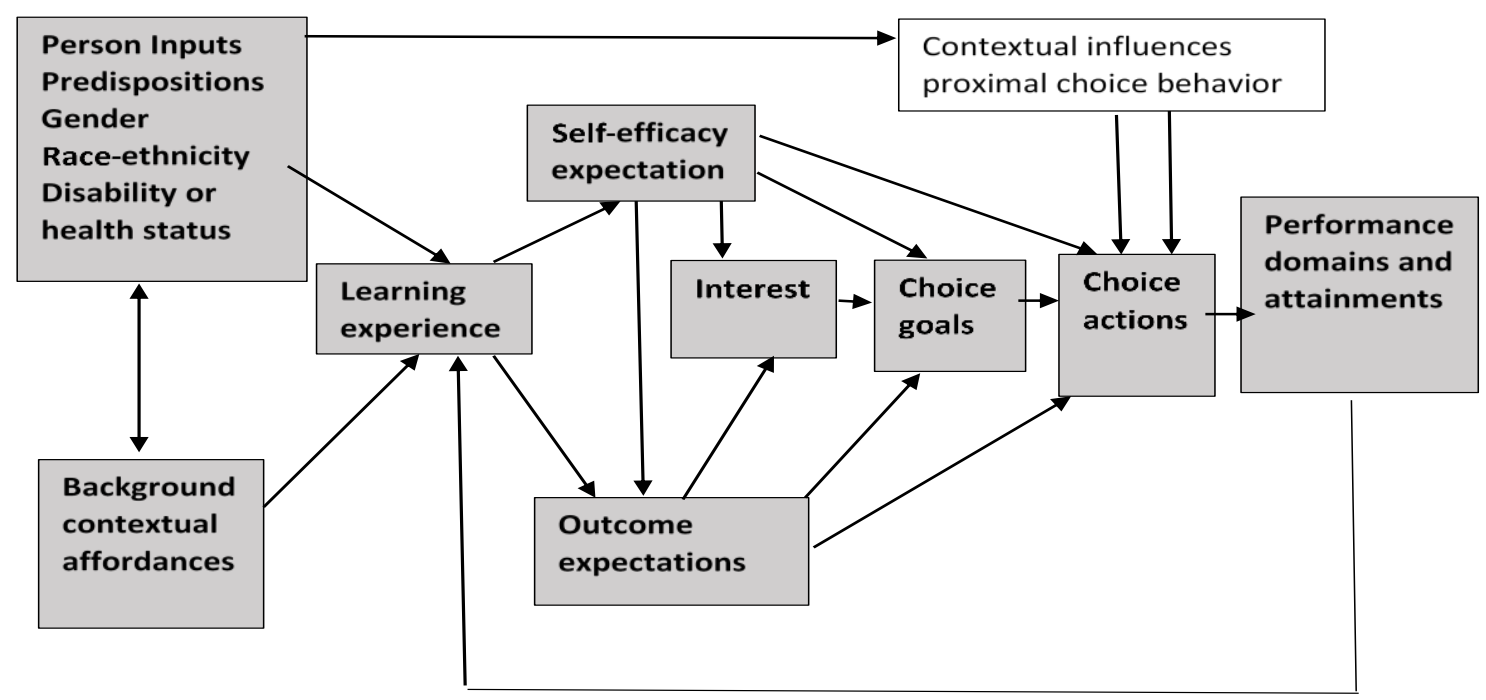

\section{Independent Variables}

To answer the three research questions the following variables were selected from the LSAY as defined through the SCCT framework. See Table 1.

SCCT defines person inputs as innate traits of race, gender, physical appearance, special abilities such as intelligence or artistic ability, or any physical disabilities (Lent, et al., 1994). LSAY variables measured under this construct were gender and race/ethnicity. The LSAY used a dummy code for females as 1 and males as 2. Race/ethnicity was recoded as a binary variable with 0 representing students who were Hispanic, Black, Asian, and Native American and 1 representing White students who were.

Background contextual affordances are the opportunities, resources, barriers, or affordances presented by external environmental variables that may be subject to individual interpretation and access to learning experiences (Byers \& Hackett, 1998). The LSAY variable used under this construct was socioeconomic status. The LSAY did not have a distinct variable for socioeconomic status. A composite variable was created for this study by data items of, father and mother employment status, highest educational 
level of parent (s) in the household, and parent employment in a STEMM (science, technology, engineering, mathematics, or medicine) profession or in a STEMM support position. Using definitions by Miller and Solberg (2012), STEMM professionals were assumed to have a higher income than those employed in STEMM support positions or not employed in a STEMM field at all. The variable was recoded into a 7-point scale, ranged from 1(low) to 7 (high) socioeconomic status. Learning experiences include, vicarious learning, verbal persuasion, an affective reaction (anxiety) or past performance (Bandura, 1977). For this study, learning experiences of verbal persuasion was the main interest and focus. Verbal persuasion includes constructive and meaningful encouragement and is most influential when the sources are credible to the recipient. (Bandura, 1986). The LSAY variables measured were verbal encouragement or "push" of peers, parents and teachers, mathematics teachers, and science teachers. The variables reflected questionnaire items that asked the students to respond to the amount of encouragement they received from these individuals to attend college, perform well in mathematics, science, and, in overall academics. Parent push variables were measured on a scale from 1-5 with the lowest score representing student perceived low push. Peer push variables were scored using a 5-point scale 0 as low push. Perceived college push from teachers was scored on a 7-point scale with high push scored at 7. Perceived student push from math and science teachers was scored similarly with a 6-point scale.

Self-efficacy is defined as the belief that one has regarding the ability to perform a specific action (Bandura, 1986). Several LSAY variables measured self-efficacy in relation to career choice, action and career performance attainment. LSAY variables selected were; "I am good at math," "I like math," "I am good at science," "I like 
science," and "I am good student overall." Preliminary statistical analysis indicated multicollinearity, resulting in the creation of a composite variable which is discussed further in Chapter Four.

Outcome expectations are defined as the anticipated benefits a person receives resulting from performing a given action (Bandura, 1986). The variable selected from the LSAY were the student's expectations of their highest education level post high school to achieve desired career. Table 1 is a list of the independent variables used in this study.

Table 1.

Independent Variables

\begin{tabular}{|c|c|c|c|c|}
\hline $\begin{array}{l}\text { SCCT } \\
\text { construct }\end{array}$ & Variable & Definition & $\frac{\text { Variable }}{\text { Coding }}$ & $\underline{\text { Source/Type }}$ \\
\hline $\begin{array}{l}\text { Person } \\
\text { inputs }\end{array}$ & Gender & Gender of participant & $\begin{array}{l}\text { Female }=0, \\
\text { Male }=1\end{array}$ & $\begin{array}{l}\text { Initial Parent } \\
\text { questionnaire }\end{array}$ \\
\hline $\begin{array}{l}\text { Person } \\
\text { inputs }\end{array}$ & $\begin{array}{l}\text { Race/ } \\
\text { Ethnicity }\end{array}$ & $\begin{array}{l}\text { Race/ethnicity categories; } \\
\text { Hispanic, Black, White, } \\
\text { Asian, Native American }\end{array}$ & $\begin{array}{l}\text { 0=Hispanic, } \\
\text { Black, Asian, } \\
\text { Native } \\
\text { American } \\
\text { 1=White }\end{array}$ & $\begin{array}{l}\text { Initial Parent } \\
\text { questionnaire }\end{array}$ \\
\hline $\begin{array}{l}\text { Background } \\
\text { contextual } \\
\text { affordances }\end{array}$ & $\begin{array}{l}\text { SES } \\
\text { (socioeco } \\
\text { nomic } \\
\text { status) }\end{array}$ & $\begin{array}{l}\text { Composite variable: } \\
\text { mother employed, father } \\
\text { employed, mother or } \\
\text { father employed as a } \\
\text { STEMM professional, in a } \\
\text { STEMM support position, } \\
\text { or neither }\end{array}$ & 1=low 7=high & $\begin{array}{l}\text { Parent annual } \\
\text { phone } \\
\text { interview in } \\
\text { high school }\end{array}$ \\
\hline \multirow[t]{2}{*}{$\begin{array}{l}\text { Learning } \\
\text { experiences } \\
\text { of verbal } \\
\text { persuasion }\end{array}$} & $\begin{array}{l}\text { Peer } \\
\text { college } \\
\text { push }\end{array}$ & $\begin{array}{l}\text { Summary measure of the } \\
\text { number of times students } \\
\text { reported that their friends } \\
\text { encouraged them to attend } \\
\text { college in high school }\end{array}$ & $\begin{array}{l}0=\text { low push } 4= \\
\text { high push }\end{array}$ & $\begin{array}{l}\text { Student } \\
\text { questionnaire } \\
\text { fall and spring } \\
\text { in high school }\end{array}$ \\
\hline & $\begin{array}{l}\text { Parent } \\
\text { academic } \\
\text { push }\end{array}$ & $\begin{array}{l}\text { Summary measure of the } \\
\text { student's report of how } \\
\text { much their parents } \\
\text { encouraged them } \\
\text { academically in high } \\
\text { school }\end{array}$ & $\begin{array}{l}1=\text { low push } \\
5=\text { high push }\end{array}$ & $\begin{array}{l}\text { Student } \\
\text { questionnaire } \\
\text { fall and spring } \\
\text { in high school }\end{array}$ \\
\hline
\end{tabular}




\begin{tabular}{|c|c|c|c|c|}
\hline & $\begin{array}{l}\text { Parent } \\
\text { college } \\
\text { push }\end{array}$ & $\begin{array}{l}\text { Summary measure of the } \\
\text { student's report of how } \\
\text { much their parents } \\
\text { encouraged them to attend } \\
\text { college because they } \\
\text { would be very } \\
\text { disappointed in them if } \\
\text { not attained }\end{array}$ & $\begin{array}{l}1=\text { low push, } \\
5=\text { high push }\end{array}$ & $\begin{array}{l}\text { Student } \\
\text { questionnaire } \\
\text { fall and spring } \\
\text { in high school }\end{array}$ \\
\hline & $\begin{array}{l}\text { Parent } \\
\text { math } \\
\text { push }\end{array}$ & $\begin{array}{l}\text { Summary measure of the } \\
\text { student's report of how } \\
\text { much their parents } \\
\text { encouraged them in math } \\
\text { in high school }\end{array}$ & $\begin{array}{l}1=\text { low push, } \\
5=\text { high push }\end{array}$ & $\begin{array}{l}\text { Student } \\
\text { questionnaire } \\
\text { fall and spring } \\
\text { of each year }\end{array}$ \\
\hline & $\begin{array}{l}\text { Parent } \\
\text { science } \\
\text { push }\end{array}$ & $\begin{array}{l}\text { Summary measure of the } \\
\text { student's report of how } \\
\text { much their parents } \\
\text { encouraged them in } \\
\text { science in high school }\end{array}$ & $\begin{array}{l}1=\text { low push } \\
5=\text { high push }\end{array}$ & $\begin{array}{l}\text { Student } \\
\text { questionnaire } \\
\text { fall in high } \\
\text { school }\end{array}$ \\
\hline & $\begin{array}{l}\text { Teacher } \\
\text { college } \\
\text { push }\end{array}$ & $\begin{array}{l}\text { Summary measure of } \\
\text { students report of how } \\
\text { many times their math and } \\
\text { science teachers expected } \\
\text { them to go to college in } \\
\text { high school }\end{array}$ & $\begin{array}{l}\text { 1=low push, } \\
7=\text { high push }\end{array}$ & $\begin{array}{l}\text { Student } \\
\text { questionnaire } \\
\text { fall and spring } \\
\text { in high school }\end{array}$ \\
\hline & $\begin{array}{l}\text { Math } \\
\text { teacher } \\
\text { push }\end{array}$ & $\begin{array}{l}\text { Summary measure of the } \\
\text { students report on how } \\
\text { much their math teacher } \\
\text { encouraged them in math } \\
\text { in high school }\end{array}$ & $\begin{array}{l}1=\text { low push } \\
3=\text { high push }\end{array}$ & $\begin{array}{l}\text { Student } \\
\text { questionnaire } \\
\text { fall and spring } \\
\text { in high school }\end{array}$ \\
\hline & $\begin{array}{l}\text { Science } \\
\text { teacher } \\
\text { push }\end{array}$ & $\begin{array}{l}\text { Summary measure of the } \\
\text { student's report on how } \\
\text { much their science teacher } \\
\text { encouraged them in } \\
\text { science }\end{array}$ & $\begin{array}{l}1=\text { low push } \\
6=\text { high push }\end{array}$ & $\begin{array}{l}\text { Student } \\
\text { questionnaire } \\
\text { fall and spring } \\
\text { in high school }\end{array}$ \\
\hline Self-efficacy & $\begin{array}{l}\text { Self- } \\
\text { efficacy }\end{array}$ & $\begin{array}{l}\text { Composite variable: } \\
\text { Students report; I am good } \\
\text { at math, I like math, I am } \\
\text { good at science, I like } \\
\text { science, I am a good } \\
\text { student overall }\end{array}$ & 1=low, $5=$ high & $\begin{array}{l}\text { Student } \\
\text { questionnaire } \\
\text { fall and spring } \\
\text { in high school }\end{array}$ \\
\hline
\end{tabular}




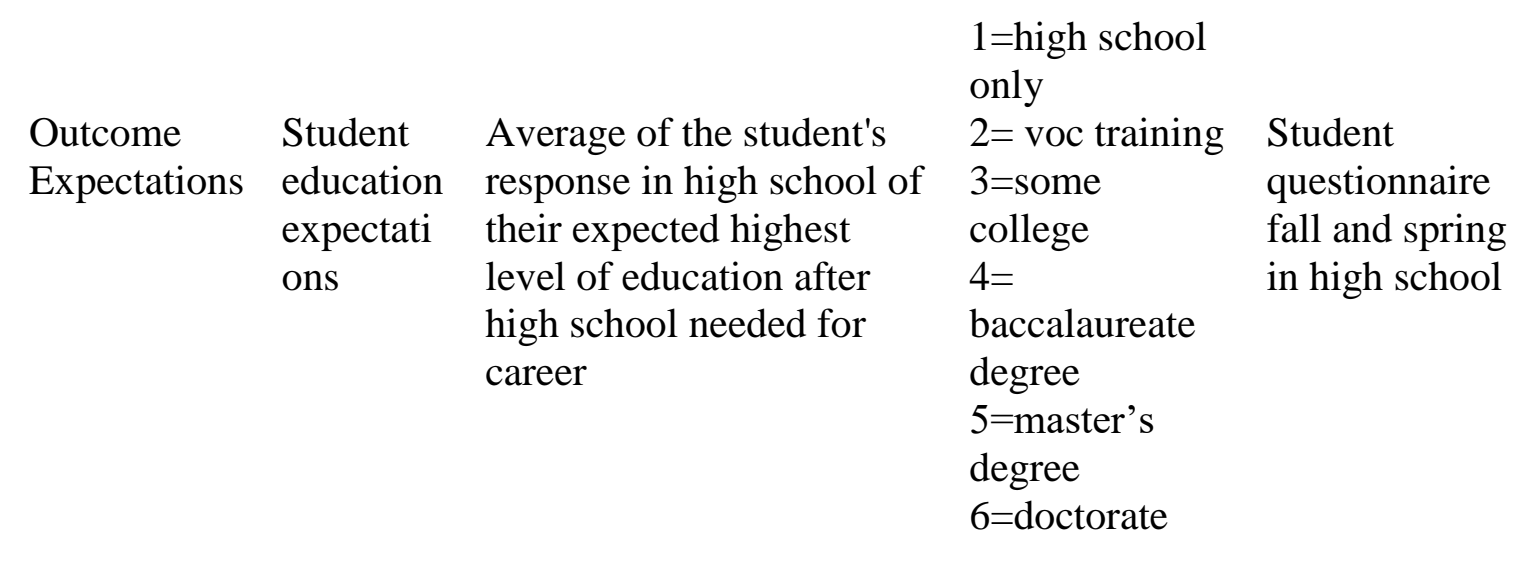

\section{Dependent Variables}

Career interests, as postulated through SCCT, are developed through early exposure to a wide array of activities of potential career relevance, both directly and vicariously. These activities are differentially reinforced for pursuing certain activities from among those that are possible and for achieving satisfactory performance (Lent, Brown, \& Hackett, 1994). Further, SCCT explains that an individual's occupational or academic interests at any point in time are reflective of his or her concurrent self-efficacy beliefs and outcome expectations (Lent, Brown, \& Hackett, 1994).

For the dependent variable for the first research question, the LSAY variable that reflected career interest within the SCCT framework was the students' response to a questionnaire close to high school graduation, about what their future career would be. As stated previously, the LSAY staff coded responses using the 1970 Occupational Classification system devised by the US Census Bureau. The LSAY staff then grouped occupations into categories of professions under this variable. Health care was divided into two categories; health professionals I and health professionals II. Using similar definitions used to differentiate STEMM professionals from STEMM support positions, occupations coded as health professionals I were defined as exercising individual and 
group judgment about scientific and technical decisions (Miller \& Solberg, 2012).

Included in this category were physicians, dentists, veterinarians, and nurses with a master's degree or higher (Miller \& Solberg, 2012). Occupations that carried out the instructions and procedures set forth by those occupations included in the latter category, were categorized as health professionals II. Health professionals II included laboratory technicians, therapists, radiology and other technicians, and nurses with less than a master's degree (Miller \& Solberg, 2012). Miller and Solberg (2012) explained the differentiation between a nurse who was a STEMM professional and one who was a STEMM support person was based on level of education, however they expressed that more detailed information about the actual roles performed would have been preferred. They further clarified, that kind of functional information was not available for analysis and therefore an arbitrary decision was made.

For purposes of this study, this variable was recoded to capture all the participants expressed interest in a future health care careers. Both groups of health professionals were combined to create a binary dependent variable; interest in health care career or not.

The second dependent variable for the first research question was high school achievement scores. This variable was the mean of students' high school science, mathematics, and reading percentile scores. This dependent variable fit within the SCCT model as a choice action. Choice actions are entry behaviors towards a performance domain and career attainment. Although, SCCT shows a direct path whereby choice actions are influenced by interests and goals, SCCT postulates a pathway where selfefficacy beliefs and outcome expectations may also influence choice actions. Therefore, the selection of this dependent variable was to test this pathway of the model. The 
literature has been clear that the lack of achievement in core subject areas of mathematics, science, and reading are barriers to post-secondary education and pursuit of a nursing/health care provider degree (Archbald \& Farley-Ripple, 2012; Loftin, et al., 2013; NCES, 2016, The Sullivan Commission, 2004; Villarruel, Canales, \& Torres, 2001). Therefore, academic achievement was considered entry behavior or a choice action to goal attainment.

The dependent variable for the second research question was the LSAY participant's positive response to a health care major in college. This information was collected the spring of their first year out of high school or, similarly, end of their first year of college. Unlike the coding for the first dependent variable of career interest, where coding reflected groups of professions (health professional I and health professional II), over fifty college majors were listed in the data file. For purposes of this study, this variable was recoded. Health care majors of nursing, pharmacy, medicine, rehabilitation, and dentistry were recoded and given a code of 1 . All non-health care majors were recoded as a 0 , thus creating a binary dependent variable for health care major the first year in college.

The dependent variable for the third research question was "registered nurse in the workforce". Data from this variable were collected from the 2007 LSAY participant response to their current occupation. As stated previously, 1970 US Census Bureau Occupation Codes were used for consistency. The code for registered nurse, 75, was easily accessible and recoded as a 1 for this study analysis with all other responses (not a registered nurse) coded as 0 , thus creating a binary variable.

A further analysis was conducted for this research question to test the model for 
LSAY participants who became a health care provider in 2007. Recoding occurred to create a binary variable; code 1 for a health care provider, code 0 , for not a health care provider (in 2007).

Table 2 lists the dependent variables used in the study. Appendix B shows of the SCCT diagram and the variables used in the study.

Table 2.

Dependent Variables

\begin{tabular}{|c|c|c|c|c|c|}
\hline $\begin{array}{l}\text { SCCT } \\
\text { construct }\end{array}$ & Question & Variable & Definition & $\frac{\text { Variable }}{\text { Coding }}$ & Source/Type \\
\hline Interests & 1 & $\begin{array}{l}\text { Interest } \\
\text { in a } \\
\text { health } \\
\text { care } \\
\text { career at } \\
\text { high } \\
\text { school } \\
\text { graduatio } \\
\text { n }\end{array}$ & $\begin{array}{l}\text { Student's } \\
\text { expressed what } \\
\text { their future career } \\
\text { would be. } \\
\text { Recoded for this } \\
\text { study into a binary } \\
\text { variable from } \\
\text { original LSAY } \\
\text { coding using the } \\
\text { 1970 US Bureau } \\
\text { Occupation } \\
\text { Classification } \\
\text { codes. }\end{array}$ & $\begin{array}{l}0=\text { no } \\
\text { interest in } \\
\text { health care } \\
\text { career, } 1= \\
\text { yes } \\
\text { interested } \\
\text { in health } \\
\text { care career }\end{array}$ & $\begin{array}{l}\text { Student } \\
\text { questionnaire } \\
\text { in the spring } \\
\text { of } 12 \text { th grade }\end{array}$ \\
\hline \multirow[t]{2}{*}{$\begin{array}{l}\text { Choice } \\
\text { Action }\end{array}$} & 1 & $\begin{array}{l}\text { High } \\
\text { school } \\
\text { achievem } \\
\text { ent scores }\end{array}$ & $\begin{array}{l}\text { Student's mean } \\
\text { high school } \\
\text { percentile scores in } \\
\text { science, } \\
\text { mathematics, and } \\
\text { reading }\end{array}$ & $\begin{array}{l}0-31 \text { Low } \\
32-50 \\
51-66 \\
67-82 \\
83-100 \\
\text { High }\end{array}$ & $\begin{array}{l}\text { A reading } \\
\text { comprehensio } \\
\mathrm{n} \text { test taken by } \\
\text { each cohort } \\
\text { the spring of } \\
\text { 12th grade. } \\
\text { Math and } \\
\text { science text } \\
\text { taken each fall } \\
\text { in high } \\
\text { school. }\end{array}$ \\
\hline & 2 & $\begin{array}{l}\text { Health } \\
\text { care } \\
\text { major in } \\
\text { college }\end{array}$ & $\begin{array}{l}\text { Student's college } \\
\text { major. Recoded } \\
\text { into a binary } \\
\text { variable from } \\
\text { original LSAY } \\
\text { coding. }\end{array}$ & $\begin{array}{l}0=\text { no } \\
\text { health care } \\
\text { major } 1= \\
\text { yes health } \\
\text { care major }\end{array}$ & $\begin{array}{l}\text { Phone } \\
\text { interview of } \\
\text { LSAY } \\
\text { participant in } \\
\text { the spring of } \\
\text { the first year }\end{array}$ \\
\hline
\end{tabular}




\begin{tabular}{|c|c|c|c|c|c|}
\hline & & & & & $\begin{array}{l}\text { out of high } \\
\text { school }\end{array}$ \\
\hline \multirow[t]{2}{*}{$\begin{array}{l}\text { Performance } \\
\text { domains and } \\
\text { attainment }\end{array}$} & 3 & $\begin{array}{l}\text { Employe } \\
\mathrm{d} \text { as a RN } \\
\text { in } 2007\end{array}$ & $\begin{array}{l}\text { Original LSAY } \\
\text { student was } \\
\text { employed as a RN } \\
\text { in } 2007 . \text { US } \\
\text { Census Bureau } \\
1970 \text { occupational } \\
\text { code for RN was } \\
75 . \text { Recoded for } \\
\text { this study as } \\
\text { binary variable. }\end{array}$ & $\begin{array}{l}0=\text { not a } \\
\text { RN } 1= \\
\text { yes a RN }\end{array}$ & $\begin{array}{l}2007 \text { phone } \\
\text { interview with } \\
\text { original } \\
\text { LSAY } \\
\text { participant } \\
\text { now an adult }\end{array}$ \\
\hline & 3 & $\begin{array}{l}\text { Employe } \\
\text { d as a } \\
\text { health } \\
\text { care } \\
\text { provider } \\
\text { in } 2007\end{array}$ & $\begin{array}{l}\text { Original LSAY } \\
\text { student was } \\
\text { employed in health } \\
\text { care in } 2007 . \\
\text { Recoded for this } \\
\text { study into a binary } \\
\text { variable from } \\
\text { original LSAY } \\
\text { coding using the } \\
\text { 1970 US Bureau } \\
\text { Occupation } \\
\text { Classification } \\
\text { codes }\end{array}$ & $\begin{array}{l}0=\text { not } \\
\text { health care } \\
\text { provider } \\
1=\text { yes a } \\
\text { health care } \\
\text { provider }\end{array}$ & $\begin{array}{l}2007 \text { phone } \\
\text { interview with } \\
\text { original } \\
\text { LSAY } \\
\text { participant } \\
\text { now an adult }\end{array}$ \\
\hline
\end{tabular}

\section{Data Analysis Plan}

Data analysis began with descriptive statistics to summarize the distribution, outliers, missing values and data entry errors for each variable. Correlations were examined for relationships among the variables. Demographic variables were analyzed to identify the sample size, gender, race, age, geographic region, community type of original school, and student socioeconomic status. The appropriate weights were applied to account for the unequal probabilities in sampling and student attrition at schools.

The study was designed to answer three research questions using the same independent variables and four different dependent variables indicative of the career continuum from high school, through college, to professional employment. 


\section{Question 1}

What is the relationship of gender, race/ethnicity, socioeconomic status, verbal encouragement (push) of peers, parents and teachers, students' self-efficacy beliefs in math and science abilities, and students' expectations for education after high school in predicting, (a) high school achievement test scores and (b) interest in a health care career at high school graduation?

This question was handled in two parts with each independent variable, high school academic achievement, and interest in a health care career, analyzed separately. Multiple regression was the statistical method used to predict high school academic achievement. It allowed for the examination of multiple independent variables and their relationship in predicting the dependent variable (high school achievement). It allowed for analysis on two levels; how well the multiple independent variables related to each other in predicting the outcome while also informing how important each predictor was in relation to the outcome (Harlow, 2014). Significance was set at $.05(\mathrm{p}<.05)$.

Logistic regression was the statistical method used to predict the binary dependent variable, interest in a health career at high school graduation. Logic regression, also a multivariate prediction method, was used to predict the odds of falling into the desired outcome. Significance was set at $.05(\mathrm{p}<.05)$. Logistic regression is the appropriate method for multivariate prediction of a binary variable (Harlow, 2014).

\section{Question 2}

What is the relationship of gender, race/ethnicity, socioeconomic status, verbal encouragement (push) of peers, parents and teachers, students' self-efficacy beliefs in math and science abilities, and students' expectations for education after high school in predicting a health care major the first year of college? Logistic regression was 
conducted to predict health care college major with the dependent variables listed above. Significance was set at $.05(\mathrm{p}<.05)$.

\section{Question 3}

What is the relationship of gender, race/ethnicity, socioeconomic status, verbal encouragement (push) of peers, parents and teachers, student self-efficacy beliefs in math and science abilities, and students' expectations for education after high school in predicting an (a) occupation in health care and (b) occupation as a registered nurse?

The dependent variable, entry into the workforce was recoded as a binary variable. Therefore, logistic regression was the statistical method used to determine the odds of the multiple independent variables in predicting entry into the workforce. Significance was set at $.05(\mathrm{p}<.05)$.

\section{Further Analysis}

Does an interest in a health care career at the end of high school and a health care major the first year of college predict entry into the nursing workforce?

Logistic regression was conducted to analyze this question. Significance was set at $.05(\mathrm{p}<.05)$.

\section{Considerations of Secondary Data Analysis}

In the design of this study, several factors had to be considered in using the LSAY for this secondary analysis. First, the LSAY was not designed to specifically look at predictors of a career in nursing. Nursing career was implied in several variables and explicitly identified in others. To organize this information for the purposes of the original study, the LSAY authors created categories and codes based on the best available resources at the time. Therefore, for the present study, a 'deep dive' into the selected 
outcome variables was conducted. This required an in-depth understanding of the original investigators' rationale and the identification of the resources used in their decision making for categorizing and coding. This resulted in recoding the dependent variables to identify nursing or health care as an interest, college major, and current occupation in 2007.

Recoding was also done for the continuous independent variables. The LSAY originally coded ordinal variables with the highest number assigned to the less desirable response. In the case of the variable measuring "push" or persuasion, low push was coded at the highest response of 5. Therefore, for the purposes of this study and ease in analysis, the variables were recoded whereas the less desirable response was the lowest assigned number of 1 or 0 . The variance in categories remained.

Nonetheless, the LSAY provided a rich data set to examine social cognitive predictors that fit well within the SCCT framework to investigate health career trajectories of high school adolescents commonly referred to as Generation X.

\section{Summary}

This chapter presented the national data set, the Longitudinal Study of American Youth, the study design, the two-cohort sample, variable selections and coding, and the data analysis plan for the study. This chapter also described the challenges posed by the secondary analysis of an established data set. 


\section{CHAPTER IV:}

\section{RESULTS}

This chapter presents a description of the demographic characteristics of the LSAY sample used in the study followed by descriptive statistics of the variables, and results of preliminary statistical analysis. A brief description of the procedures on recoding specific variables and the rationale for that process is discussed. Lastly, each research question is presented followed by the statistical analyses and results.

\section{Sample}

The sample consisted of 4009 LSAY students from Cohort One and Cohort Two who also completed the 2007 occupational survey. The sample was a national representative sample of age-appropriate high school students who participated in the longitudinal LSAY study for seven consecutive years of data collection, ending 1 year (Cohort One) to 4 years (Cohort Two) after high school. Both cohorts were contacted 13 years later, then 33 to 37 years of age, to ask about their employment status and current occupation. Thus, the sample represents the pre-collegiate pipeline from high school to college to entry into the health professions workforce. See Table 3 for complete demographic characteristics of the sample. Table 4 depicts a breakdown by race and ethnicity of the participants' occupational interest, college major and 2007 occupation.

Demographic Characteristics of LSAY Sample (N=4009)

\begin{tabular}{ccccc}
\hline \multicolumn{1}{c}{ Characteristics } & $\frac{\text { Gender }}{\text { female }}$ & male & - & $\frac{\text { Total }}{\%}$ \\
Race/Ethnicity & & & & \\
Hispanic & 142 & 141 & 283 & $7 \%$ \\
Black & 202 & 127 & 329 & $8 \%$ \\
White & 1597 & 1398 & 2995 & $75 \%$ \\
Asian & 63 & 62 & 125 & $3 \%$
\end{tabular}


Career

Native American

26

19

45

interest at

high school

graduation

Health care career

$416 \quad 199 \quad 615 \quad 15 \%$

Non-health care career $\quad 1706 \quad 1688 \quad 3394 \quad 85 \%$

College

Major

Health care major

$\begin{array}{lll}115 & 37 \quad 152 \quad 4 \%\end{array}$

Non-health care major

$2007 \quad 1850 \quad 3857 \quad 96 \%$

2007

Occupation

Health care provider

$\begin{array}{lll}165 & 59 & 224\end{array}$

Not a health care

provider

1957

$1828 \quad 3786 \quad 94 \%$

Registered Nurse

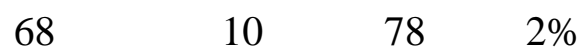

Not a registered nurse

$2054 \quad 1877 \quad 3931 \quad 98 \%$

Note. Numbers 1, 2, 3 indicate three time points of the health care career pipeline

Table 4.

Demographic Characteristics of Health Care Career Interest and Occupation by Race/Ethnicity

\begin{tabular}{|c|c|c|c|c|c|}
\hline Race/Ethnicity & $\frac{\frac{\text { Interest in }}{\text { health care }}}{\underline{\text { career }}}$ & $\begin{array}{l}\frac{\text { Health }}{\text { care }} \\
\text { major in } \\
\text { college }\end{array}$ & $\begin{array}{l}\frac{\text { Health care }}{\text { provider in }} \\
\frac{\text { workforce }}{(2007)}\end{array}$ & $\frac{\frac{\mathrm{RN} \text { in }}{\text { workforce }}}{\underline{(2007)}}$ & Total \\
\hline Hispanic & 32 & 8 & 13 & 6 & 283 \\
\hline Black & 72 & 17 & 24 & 3 & 329 \\
\hline White & 452 & 111 & 156 & 62 & 2995 \\
\hline Asian & 34 & 8 & 17 & 2 & 125 \\
\hline $\begin{array}{l}\text { Native } \\
\text { American }\end{array}$ & 5 & 1 & 3 & 2 & 45 \\
\hline
\end{tabular}




\begin{tabular}{lccccr} 
Totals & 595 & 145 & 213 & 93 & 3,777 \\
\hline Note. Totals do not equal 4009 & because & 232 & $(5.8 \%)$ & of participants did not answer
\end{tabular}

\section{Study Variables}

Study variables selection was guided by the theoretical framework of the Career Choice Model of the Social Cognitive Career Theory (Lent et al., 1994). See Appendix B for illustration of SCCT with study aims and pipeline time points. Several of the variables required recoding because; (1) the original coding of some LSAY variables was not suitable to address the research questions in this study, and (2) LSAY protocol data were collected that could be combined to create a composite variable for analysis, (3) the statistical method most appropriate to address the research questions required it. A composite variable for participants' socioeconomic status was created from; father employed in the workforce, mother employed in the workforce, highest educational level of parent (s) in the household, and parent employment in a STEMM profession or STEMM support position (Miller \& Solberg,1986). The alpha coefficient for the SES variable reliability was .70. Definitions of STEMM professions and STEMM support positions were described in Chapter 3.

Several LSAY variables met the SCCT definition under the self-efficacy construct. They included; "I like math", "I am good at math", "I like science", "I am good at science", "I am a good student overall." Correlations among the variables were found to be moderately high at a coefficient of .65 , however multicollinearity was not found.

All the dependent variables were recoded except for high school academic achievement. As described in Chapter 3, student responses regarding occupational choice and college major allowed for open ended responses and were coded by LSAY staff using 
the 1970 occupation codes as devised by the US Census Bureau (1970) and a college major software dictionary file. (Miller, 2014). These LSAY codes were recoded into binary variables for logistic regression analysis in this study.

The descriptive statistics of the study variables representing the elements of the theoretical model are shown in Table 5.

Table 5.

Descriptive Statistics for the Study Variables

\begin{tabular}{|c|c|c|c|c|c|}
\hline Independent & & & & & Std. \\
\hline Variables & $\underline{N}$ & $\underline{\text { Minimum }}$ & Maximum & Mean & Deviation \\
\hline $\begin{array}{l}\text { High school academic } \\
\text { scores (math, science, } \\
\text { reading) }\end{array}$ & 3996 & 0.0 & 100.00 & 57.50 & 25.00 \\
\hline SES & 3934 & 1.00 & 7.00 & 3.64 & 1.39 \\
\hline Peer college push & 4009 & 0.00 & 4.00 & 2.53 & 1.32 \\
\hline Parent academic push & 4008 & 1.00 & 5.00 & 3.17 & 1.24 \\
\hline Parent college push & 4009 & 1.00 & 5.00 & 3.08 & 0.99 \\
\hline Parent math push & 4008 & 1.00 & 3.00 & 2.39 & 0.77 \\
\hline Parent science push & 4009 & 1.00 & 5.00 & 2.21 & 1.19 \\
\hline Teacher college push & 3798 & 1.00 & 7.00 & 2.47 & 1.85 \\
\hline Math teacher push & 3959 & 1.00 & 6.00 & 4.23 & 1.63 \\
\hline Science teacher push & 4009 & 1.00 & 6.00 & 3.47 & 1.94 \\
\hline Self-efficacy & 2139 & .80 & 4.60 & 3.26 & 0.69 \\
\hline $\begin{array}{l}\text { Student Education } \\
\text { Expectations }\end{array}$ & 3928 & 1.00 & 6.00 & 3.94 & 1.39 \\
\hline
\end{tabular}

Note. $\mathrm{N}$ may not equal 4009 because of missing data

Preliminary statistical analysis was conducted to test normality, homoscedasticy, and linearity. The test of homogeneity of variance indicated normal distributions across variables and skewness and kurtosis were not above 3. Correlations among the variables 
were analyzed. Issues of multicollinearity were examined among the independent variables and there was no duplication of variables with no correlations above .60 . There were a number of variables that were moderate to highly correlated. High school achievement scores were correlated with peer college push $r=.42, p=<0.01$ and students' educational expectations after high school $r=.47, p=<0.01$. Math teacher push was highly correlated with science teacher push $r=.50 . p=<0.01$. Health care occupation was highly correlated with $\mathrm{RN}$ occupation $r=.58, p=<0.01$. See Appendix $\mathrm{C}$ for correlations among the variables.

\section{Research Question 1}

What is the relationship of gender, race/ethnicity, socioeconomic status, verbal encouragement (push) of peers, parents and teachers, student self-efficacy beliefs in math and science abilities, and students' expectations for education after high school in predicting; (a) high school achievement test scores and (b) interest in a health care career at high school graduation?

\section{Question 1a.}

Multiple regression analysis was conducted to investigate the predictors of high school academic achievement scores. The model was significant $F(13,2096)=85.64$, $p<.05, R^{2}=.35$. Significant predictors of high school achievement were; gender (males), race/ethnicity, peer college push, parent academic push, parent college push, parent math push, teacher college push, math teacher push, student self-efficacy beliefs, and student educational expectations after high school (see Table 6). The strongest predictors of high school academic achievement were White race $(B=.63)$, student self-efficacy beliefs in math and science abilities $(B=.38)$ and student educational expectations after high school 
$(B=.24)$. Parent academic push was significant, but the coefficient was negative $(B=-.16)$ indicting that parent push in academics predicted lower scores. Science teacher push approached significance $(p=.05)$ with a negative coefficient $(B=-.03)$ indicating the more science teachers pushed, the lower the achievement scores. Only one variable, parent science push, was not significant ( $\mathrm{p}=.126)$. Table 6 presents the summary of results predicting academic achievement in high school.

Table 6 .

Summary Multiple Regression Analysis: Predicting Reading, Math, Science Achievement in $H S$

\begin{tabular}{|c|c|c|c|c|c|c|c|}
\hline \multirow{2}{*}{$\underline{\text { Variables }}$} & \multirow{2}{*}{$\underline{B}$} & \multirow{2}{*}{$\underline{\mathrm{SE}}$} & \multirow{2}{*}{ Beta } & \multirow{2}{*}{$\underline{t}$} & \multirow{2}{*}{$\mathrm{p}$} & \multicolumn{2}{|c|}{$95 \% \mathrm{CI}$ for $\operatorname{EXP}(\mathrm{B})$} \\
\hline & & & & & & Lower & Higher \\
\hline Gender & .19 & .05 & .07 & 3.77 & .000 & .09 & .28 \\
\hline Race/Ethnicity & .63 & .06 & .20 & 11.02 & .000 & .52 & .74 \\
\hline SES & .13 & .02 & .13 & 6.82 & .000 & .09 & .16 \\
\hline $\begin{array}{l}\text { Peer college } \\
\text { push }\end{array}$ & .11 & .03 & .09 & 4.24 & .000 & .06 & .16 \\
\hline $\begin{array}{l}\text { Parent } \\
\text { academic push }\end{array}$ & -.16 & .02 & -.14 & -7.08 & .000 & -.21 & -.12 \\
\hline $\begin{array}{l}\text { Parent college } \\
\text { push }\end{array}$ & .07 & .03 & .05 & 2.54 & .011 & .02 & .13 \\
\hline $\begin{array}{l}\text { Parent math } \\
\text { push }\end{array}$ & .09 & .04 & .05 & 2.03 & .042 & .00 & .18 \\
\hline $\begin{array}{l}\text { Parent science } \\
\text { push }\end{array}$ & .04 & .03 & .04 & 1.53 & .126 & -.01 & .09 \\
\hline $\begin{array}{l}\text { Teacher } \\
\text { college push }\end{array}$ & .04 & .02 & .05 & 2.43 & .015 & .01 & .07 \\
\hline $\begin{array}{l}\text { Math teacher } \\
\text { push }\end{array}$ & .09 & .02 & .09 & 4.42 & .000 & .05 & .13 \\
\hline $\begin{array}{l}\text { Science } \\
\text { teacher push }\end{array}$ & -.03 & .02 & -.04 & -1.99 & .047 & -.06 & .00 \\
\hline Self-efficacy & .38 & .04 & .19 & 9.55 & .000 & .30 & .45 \\
\hline $\begin{array}{l}\text { Student } \\
\text { expected } \\
\text { highest level } \\
\text { of education }\end{array}$ & .24 & .02 & .23 & 9.76 & .000 & .19 & .29 \\
\hline
\end{tabular}


Note. $\mathrm{p}<$ at the 0.05 level

\section{Question 1b.}

Logistic regression analysis was conducted to investigate the same independent variables in predicting students' interest in a health care career at high school graduation, the first step of the career pipeline. The model was significant, $\mathrm{p}<.05$, Nagelkerke $R^{2}=.20$. Results revealed a $20 \%$ improvement in understanding the development of this phenomena. From an examination of the odds ratios and their respective confidence intervals, there were slightly greater odds of student's interest in a health care career at high school graduation if the student had expectations for education after high school (O.R.=1.71; 95\% CI 1.50-1.95) perceived push from their parents in science (O.R.=1.39; 95\% CI 1.22-1.58), and held self-efficacy beliefs in their math and science abilities (O.R.=1.31, 95\% CI 1.08-1.59). All three of these predictors were significant. The model also showed that female gender, race (other than White), parent college push, parent math and science push were significant. Socioeconomic status, peer and parent college push, parent academic push, and pushes from teachers were not significant predictors in student's interest in a health care career at high school graduation. Table 7 describes a summary of findings.

Table 7.

Summary Logistic Regression Analysis: Predicting Interest in Health Care Career at HS Graduation

\begin{tabular}{|c|c|c|c|c|c|c|c|}
\hline \multirow{3}{*}{$\underline{\text { Variables }}$} & \multirow{3}{*}{$\underline{\mathrm{B}}$} & \multirow{3}{*}{$\underline{\mathrm{SE}}$} & \multirow{3}{*}{$\frac{\text { Wald }}{\underline{\text { Statistics }}}$} & \multirow{3}{*}{$\underline{\mathrm{p}}$} & \multirow{3}{*}{$\underline{\operatorname{Exp}(B)}$} & \multicolumn{2}{|c|}{$95 \%$ CI for } \\
\hline & & & & & & $\underline{\operatorname{EXP}(B)}$ & Lower \\
\hline & & & & & & \multicolumn{2}{|c|}{ Higher } \\
\hline Gender & -.83 & .13 & 41.66 & .000 & .44 & .34 & .56 \\
\hline Race/Ethnicity & -.33 & .14 & 5.20 & .023 & .72 & .55 & .96 \\
\hline SES & .02 & .05 & .26 & .610 & 1.02 & .94 & 1.12 \\
\hline
\end{tabular}




\begin{tabular}{lccccccc}
$\begin{array}{l}\text { Peer college } \\
\text { push }\end{array}$ & -.06 & .07 & .82 & .365 & .94 & .82 & 1.08 \\
$\begin{array}{l}\text { Parent } \\
\text { academic push }\end{array}$ & .00 & .06 & .00 & .944 & 1.00 & .89 & 1.11 \\
$\begin{array}{l}\text { Parent college } \\
\text { push }\end{array}$ & .17 & .07 & 5.19 & .023 & 1.18 & 1.02 & 1.37 \\
$\begin{array}{l}\text { Parent math } \\
\text { push }\end{array}$ & -.37 & .12 & 9.82 & .002 & .69 & .55 & .87 \\
$\begin{array}{l}\text { Parent science } \\
\text { push }\end{array}$ & .33 & .07 & 24.67 & .000 & 1.39 & 1.22 & 1.58 \\
$\begin{array}{l}\text { Teacher } \\
\text { college push }\end{array}$ & .02 & .04 & .19 & .665 & 1.02 & .94 & 1.10 \\
$\begin{array}{l}\text { Math teacher } \\
\text { push }\end{array}$ & .01 & .05 & .01 & .918 & 1.01 & .90 & 1.12 \\
$\begin{array}{l}\text { Science } \\
\text { teacher push }\end{array}$ & .03 & .04 & .65 & .419 & 1.03 & .96 & 1.12 \\
$\begin{array}{l}\text { Self-efficacy } \\
\text { Student }\end{array}$ & .27 & .10 & 7.36 & .007 & 1.31 & 1.08 & 1.59 \\
$\begin{array}{l}\text { expected } \\
\text { highest level } \\
\text { of education }\end{array}$ & .54 & .07 & 63.59 & .000 & 1.71 & 1.50 & 1.95 \\
\hline
\end{tabular}

\section{Research Question 2}

What is the relationship of gender, race/ethnicity, socioeconomic status, verbal encouragement (push) of peers, parents and teachers, students' self-efficacy beliefs in their math and science abilities, and students 'expectations for education after high school in predicting a health care major the first year of college.

Logistic regression analysis was conducted to investigate the independent variables predicting a health care major the first year of college, the second step of the pipeline. The model was significant $\mathrm{p}<.05$, Nagelkerke $R^{2}=.15$. The significant predictors were; gender (female), perceived encouragement (push) from parents in science, students' self- efficacy beliefs about their abilities in math and science, and their educational expectations after high 
school. From an examination of the odds ratios and their respective confidence intervals, there were slightly greater odds of a health care college major when students expressed self-efficacy beliefs in the math and science abilities (O.R.=1.59; 95\#CI 1.10-2.28), had expectations of education after high school (O.R.=1.40; 95\% CI 1.10-1.77) and perceived push in science from their parents (O.R.=1.31; 95\% CI 1.04-1.63). Race/ethnicity, socioeconomic status, peer college push, parent academic push, parent college push, parent math push and teachers' push were not significant in predicting a health care college major. Table 8 has a summary of the logistic regression results.

Table 8.

Summary Logistic Regression Analysis: Predicting Health Care College Major

\begin{tabular}{|c|c|c|c|c|c|c|c|}
\hline \multirow{3}{*}{$\underline{\text { Variables }}$} & \multirow{3}{*}{$\underline{\mathrm{B}}$} & \multirow{3}{*}{$\underline{\mathrm{SE}}$} & \multirow{3}{*}{$\underline{\text { Wald }}$} & \multirow{3}{*}{$\underline{p}$} & \multirow{3}{*}{$\underline{\operatorname{Exp}(B)}$} & \multicolumn{2}{|c|}{$95 \%$ CI for } \\
\hline & & & & & & $\mathrm{EXP}(\mathrm{B})$ & Lower \\
\hline & & & & & & \multicolumn{2}{|c|}{ Higher } \\
\hline \multirow{2}{*}{$\begin{array}{l}\text { Gender } \\
\text { Race/Ethnicity }\end{array}$} & -1.08 & 0.24 & 20.47 & .000 & .34 & .21 & .54 \\
\hline & -0.27 & 0.25 & 1.22 & .270 & .76 & .47 & 1.24 \\
\hline SES & 0.11 & 0.08 & 2.14 & .144 & 1.12 & .96 & 1.30 \\
\hline $\begin{array}{l}\text { Peer college } \\
\text { push }\end{array}$ & 0.14 & 0.14 & 0.93 & .334 & 1.15 & .87 & 1.53 \\
\hline $\begin{array}{l}\text { Parent } \\
\text { academic push }\end{array}$ & 0.04 & 0.10 & 0.17 & .680 & 1.04 & .85 & 1.28 \\
\hline $\begin{array}{l}\text { Parent college } \\
\text { push }\end{array}$ & -0.01 & 0.13 & 0.01 & .931 & .99 & .77 & 1.27 \\
\hline $\begin{array}{l}\text { Parent math } \\
\text { push }\end{array}$ & -0.33 & 0.22 & 2.11 & .146 & .72 & .47 & 1.12 \\
\hline $\begin{array}{l}\text { Parent science } \\
\text { push }\end{array}$ & 0.27 & 0.11 & 5.46 & .019 & 1.31 & 1.04 & 1.63 \\
\hline $\begin{array}{l}\text { Teacher } \\
\text { college push }\end{array}$ & 0.09 & 0.07 & 1.99 & .158 & 1.10 & .96 & 1.24 \\
\hline $\begin{array}{l}\text { Math teacher } \\
\text { push }\end{array}$ & 0.08 & 0.11 & 0.60 & .437 & 1.09 & .88 & 1.34 \\
\hline
\end{tabular}


Science

$\begin{array}{llllllll}\text { teacher push } & 0.03 & 0.07 & 0.22 & .643 & 1.03 & .90 & 1.19\end{array}$

$\begin{array}{llllllll}\text { Self-efficacy } & 0.46 & 0.19 & 6.18 & .013 & 1.59 & 1.10 & 2.28\end{array}$

Student

expected

highest level

$0.34 \quad 0.12 \quad 7.71$

.005

1.40

1.10

1.77

of education

\section{Research Question 3}

\section{Question 3a.}

What is the relationship of gender, race/ethnicity, socioeconomic status, verbal encouragement (push) of peers, parents and teachers, student self-efficacy beliefs in math and science abilities, and students' expectations for education after high school in predicting an occupation in health care?

Logistic regression analysis was conducted to investigate the independent variables in predicting an occupation in health care, step 3 of the career model. The model was significant $\mathrm{p}<.05$, Nagelkerke $\mathrm{R}^{2}=.11$. Four of the independent variables were significant predictors; gender (female), parent math push, teacher college push, and the students' self-efficacy beliefs in their math and science abilities. From an examination of the odds ratios and their respective confidence intervals, there were slightly greater odds of a health care occupation when students held self-efficacy beliefs in their math and science abilities (O.R. $=1.64 ; 95 \%$ CI 1.19-2.26) and perceived teacher college push $(\mathrm{O} . \mathrm{R} .=1.13 ; 95 \%$ CI 1.00-1.27). Not significant predictors of a health care occupation were race/ethnicity, socioeconomic status, peer and parent college push, parent academic and science push, math and science teacher push, and students' educational expectations after high school. The results revealed many the high school influences were not 
predictive of a health care occupation in adulthood. A summary of results are in Table 9 .

Table 9.

Summary Logistic Regression Analysis: Predicting Health Care Occupation

\begin{tabular}{|c|c|c|c|c|c|c|c|}
\hline \multirow{3}{*}{$\begin{array}{l}\text { Variables } \\
\text { Gender }\end{array}$} & \multirow{3}{*}{$\begin{array}{c}\underline{B} \\
-1.09\end{array}$} & \multirow{3}{*}{$\begin{array}{l}\underline{\mathrm{SE}} \\
0.21\end{array}$} & \multirow{3}{*}{$\begin{array}{c}\frac{\text { Wald }}{\text { Statistics }} \\
25.92\end{array}$} & \multirow{3}{*}{$\begin{array}{c}\mathrm{p} \\
.000\end{array}$} & \multirow{3}{*}{$\begin{array}{c}\operatorname{Exp}(\mathrm{B}) \\
.33\end{array}$} & \multirow{2}{*}{\multicolumn{2}{|c|}{$\begin{array}{l}\frac{95 \% \text { CI for }}{\text { EXP(B) Lower }} \\
\text { Higher }\end{array}$}} \\
\hline & & & & & & & \\
\hline & & & & & & .22 & .51 \\
\hline Race/Ethnicity & -0.40 & 0.22 & 3.44 & .064 & .67 & .44 & 1.02 \\
\hline SES & -0.04 & 0.07 & 0.25 & 617 & .96 & .84 & 1.11 \\
\hline $\begin{array}{l}\text { Peer college } \\
\text { push }\end{array}$ & -0.13 & 0.11 & 1.27 & .261 & .88 & .71 & 1.10 \\
\hline $\begin{array}{l}\text { Parent } \\
\text { academic push }\end{array}$ & -0.12 & 0.09 & 1.71 & .190 & .89 & .75 & 1.06 \\
\hline $\begin{array}{l}\text { Parent college } \\
\text { push }\end{array}$ & 0.16 & 0.12 & 1.88 & .170 & 1.17 & .93 & 1.47 \\
\hline $\begin{array}{l}\text { Parent math } \\
\text { push }\end{array}$ & -0.44 & 0.18 & 5.83 & .016 & .64 & .45 & .92 \\
\hline $\begin{array}{l}\text { Parent science } \\
\text { push }\end{array}$ & 0.18 & 0.11 & 2.77 & .096 & 1.19 & .97 & 1.46 \\
\hline $\begin{array}{l}\text { Teacher } \\
\text { college push }\end{array}$ & 0.12 & 0.06 & 4.13 & .042 & 1.13 & 1.00 & 1.27 \\
\hline $\begin{array}{l}\text { Math teacher } \\
\text { push }\end{array}$ & 0.07 & 0.09 & 0.58 & .447 & 1.07 & .90 & 1.28 \\
\hline $\begin{array}{l}\text { Science } \\
\text { teacher push }\end{array}$ & 0.13 & 0.07 & 3.70 & .054 & 1.14 & 1.00 & 1.29 \\
\hline Self-efficacy & 0.49 & 0.16 & 9.08 & .003 & 1.64 & 1.19 & 2.26 \\
\hline
\end{tabular}


Student

expected

highest level

0.12

0.10

1.45

.228

1.13

.93

1.38

of education

\section{Question 3b.}

What is the relationship of gender, race/ethnicity, socioeconomic status, verbal encouragement (push) of peers, parents and teachers, student self-efficacy beliefs in math and science abilities, and students' expectations for education after high school in predicting entry into the nursing workforce?

Logistic regression analysis was conducted to investigate the independent variables in predicting entry into the nursing workforce. The logistic regression model was significant, $\mathrm{p}<.05$, Nagelkerke $\mathrm{R}^{2}=.15$. The three significant predictors were gender (female), socioeconomic status, and student self-efficacy beliefs. From an examination of the odds ratios and their respective confidence intervals, there were slightly greater odds of becoming a registered nurse when students held self-efficacy beliefs in their math and science abilities (O.R.=1.89; 95\% CI 1.11-3.22). As with predicating a health care occupation, students' educational expectations after high school were not significant. Other non-significant predictors were race/ethnicity, peer, parent and teacher college push, parent academic push, and push from parents, math, and science teachers. Findings indicate that further down the career pipeline, high school influences were less significant in predicting occupation in nursing and health care. A summary of results is in Table 10. 
Table 10.

Summary Logistic Regression Analysis Predicting: RN Occupation

\begin{tabular}{|c|c|c|c|c|c|c|c|}
\hline \multirow{3}{*}{ Variables } & \multirow{3}{*}{$\underline{B}$} & \multicolumn{3}{|c|}{ Wald } & \multirow{3}{*}{$\underline{\operatorname{Exp}(B)}$} & \multicolumn{2}{|c|}{$95 \% \mathrm{CI}$ for } \\
\hline & & $\underline{\mathrm{SE}}$ & $\underline{\text { Statistics }}$ & $\underline{p}$ & & $\underline{\operatorname{EXP}(B)}$ & Lower \\
\hline & & & & & & \multicolumn{2}{|c|}{ Higher } \\
\hline Gender & -2.10 & 0.49 & 18.59 & .000 & .12 & .05 & .32 \\
\hline Race/Ethnicity & 0.28 & 0.41 & 0.49 & .486 & 1.33 & .60 & 2.95 \\
\hline SES & -0.37 & 0.14 & 7.48 & .006 & .69 & .53 & .90 \\
\hline $\begin{array}{l}\text { Peer college } \\
\text { push }\end{array}$ & -0.02 & 0.18 & 0.01 & .905 & .98 & .68 & 1.40 \\
\hline $\begin{array}{l}\text { Parent } \\
\text { academic push }\end{array}$ & -0.11 & 0.14 & 0.61 & .434 & .89 & .68 & 1.18 \\
\hline $\begin{array}{l}\text { Parent college } \\
\text { push }\end{array}$ & -0.21 & 0.18 & 1.36 & .244 & .81 & .57 & 1.15 \\
\hline $\begin{array}{l}\text { Parent math } \\
\text { push }\end{array}$ & -0.35 & 0.30 & 1.39 & .239 & .70 & .39 & 1.26 \\
\hline $\begin{array}{l}\text { Parent science } \\
\text { push }\end{array}$ & 0.15 & 0.18 & 0.71 & .401 & 1.16 & .82 & 1.63 \\
\hline $\begin{array}{l}\text { Teacher } \\
\text { college push }\end{array}$ & 0.10 & 0.10 & 0.98 & .321 & 1.10 & .91 & 1.34 \\
\hline $\begin{array}{l}\text { Math teacher } \\
\text { push }\end{array}$ & 0.27 & 0.17 & 2.54 & .111 & 1.31 & .94 & 1.81 \\
\hline $\begin{array}{l}\text { Science } \\
\text { teacher push }\end{array}$ & 0.13 & 0.12 & 1.34 & .247 & 1.14 & .91 & 1.43 \\
\hline Self-efficacy & 0.64 & 0.27 & 5.47 & .019 & 1.89 & 1.11 & 3.22 \\
\hline $\begin{array}{l}\text { Student } \\
\text { expected } \\
\text { highest level } \\
\text { of education }\end{array}$ & 0.11 & 0.16 & 0.43 & .512 & 1.11 & .81 & 1.52 \\
\hline
\end{tabular}




\section{Further Analysis}

Does an interest in a health care career at the end of high school and a health care major the first year of college predict entry into the nursing workforce?

Logistic regression analysis was conducted to investigate the dependent variable in step one (interest in health care career at high school graduation) and the dependent variable in step 2 (college health care major) of the career pipeline in predicting entry into the nursing workforce. The logistic regression model was significant, $\mathrm{p}<.05$, Nagelkerke $\mathrm{R}^{2}=.17$. Both were significant in predicting entry into the nursing workforce. From an examination of the odds ratios and their respective confidence intervals, having an interest in health care at high school graduation increased the odds of becoming a registered nurse (O.R. $=6.87 ; 95 \%$ CI 4.04-11.69) and majoring in health care the first year of college (O.R.=4.21; 95\% CI 2.37-7.47). Table 11 has a summary of the logistic regression results.

Table 11.

Summary Logistic Regression Analysis: Predicting Registered Nurse Occupation

$\underline{\text { Variables }}$

B $\quad \underline{\text { SE }} \underline{\text { Wald }}$

Wald $p \quad \operatorname{Exp}(B) \quad \underline{\operatorname{EXP}(B) \text { Lower }}$

Interest in

Health Care

$\begin{array}{lll}1.93 & 0.27 \quad 50.50\end{array}$

.000

6.87

Higher

Career at HS

Health Care

Major in

1.44

0.29

24.05

.000

4.21

2.37

7.47

College

\section{Summary}

This chapter presented a full description of the sample and variables used in the study. Statistical results for each research question were presented based on the SCCT 
model. Research Question 1 was analyzed in two parts. The dependent variable, high school achievement scores, was analyzed using multiple regression. The second part of Question 1 used logistic regression to predict interest in a health care career at high school graduation. Research Questions 2 and 3 were analyzed using a logistic regression model. Further, logistic regression was conducted to analyze the dependent variable in step one of the career continuum (interest in health care career at high school graduation) and the dependent variable in step 2 (college health care major) in predicting registered nurse occupation. Findings were presented and each model was significant $p<.05$ in predicting the dependent variable. 


\section{CHAPTER V:}

\section{DISCUSSION, CONCLUSION, AND IMPLICATIONS}

This chapter presents a discussion of the findings of the study, its implications for research, education, nursing practice and public policy. Limitations of the study are also presented followed by a conclusion.

\section{Discussion of Findings}

Increasing the racial and ethnic diversity of the nursing and health professions workforce to reflect the nation's shifting demographics is a national priority (IOM, 2004; IOM, 2011; The Sullivan Commission, 2004, Williams et al., 2014). The literature suggests that a more diverse workforce will reduce and eliminate health disparities related to race and ethnicity. An obvious solution is for nursing education programs to graduate a greater number of diverse students. However, the lack of academic preparation in high school for many disadvantaged students of color has been attributed to high attrition and low graduation rates in nursing programs, or lack of access to any postsecondary opportunities (Fletcher \& Cox, 2012; Seago \& Spetz, 2005). The results of this study contribute to the understanding of the precollege factors that influenced students along specific points of the career pipeline; (step 1) interest in health care at high school graduation and academic achievement, (step 2) college admission and declared health care major, and (step 3) entry into the nursing/health workforce.

\section{Early Pipeline- High School}

\section{Academic Achievement}

Disadvantaged students of color often lack the basic skills of mathematics, science, and reading proficiency (NCES, 2016). This study revealed that a significant 
predictor of high school academic achievement in mathematics, science, and reading proficiency was the verbal encouragement or "push" that students received from their peers, parents, math teachers, and science teachers while in high school. Peers, parents and teachers were significant in their push for students to attend college and do well academically. Parents and math teachers push in mathematics were also significant persuasion predictors. In addition to the encouragement students received, their science and mathematics self-efficacy beliefs and their expectations to obtain a college education after high school were also significant predictors. These findings were consistent with the literature. Spera, Wentzel, \& Matto (2009) found that parents' encouragement and expectations for their children were significant predictors of their children's academic achievement. In addition, their findings revealed that minority parents' encouragement was less related to their own educational attainment whereas White parents with lower levels of education had lower education expectations for their children (Spera, Wentzel, \& Matto, 2009).

Several studies found that peers' encouragement had a direct result in student educational expectations and academic achievement if they shared the same high educational expectations (Kindermann, 2007; Lynch, Lerner, \& Leventhal, 2013). Fouad et al., (2010) found that having friends not interested in science were barriers to student achievement in science class. They also found that students perceived teachers as both barriers and supporters of achievement, thereby concluding that external influences of gender, race, ethnicity and other factors may influence perceptions (Fouad et al., 2010).

Student self-efficacy beliefs in their math and science abilities and their expectations for education after high school were strong predictors of academic 
achievement. Sommerfeld (2016) reported results that personal educational expectations played a significant role in academic achievement and degree completion among Black, White, and Hispanic students. Other studies found that parent support was related to student math/science interest and to student self-efficacy beliefs and outcomes expectations (Ferry, Foud, \& Smith, 2000; Turner et al., 2004). Research of perceived parent support among multi-ethnic middle school students found a direct relationship with student self-efficacy beliefs (Navarro et al., 2007; Turner \& Lapan, 2002). Navarro et al. (2007) investigated Mexican American middle school students' self-efficacy and outcome expectations toward math and science. They found that Mexican American girls perceived higher support from parents, teachers, and peers, however they expressed lower self-efficacy in their math/science skills than did the male students (Navarro et al., 2007). This finding supports the results of this study where self-efficacy beliefs and male gender where significant in the model for predicting academic achievement. Lastly, Turner and Conkel-Ziebel (2011) found that even though inner-city adolescents held beliefs about the importance of academic achievement, those beliefs did not often correlate into high academic performance in part because pervasive stress can lead to the belief that success is not a product of effort.

\section{Interest in Health Care Career}

Findings of this study revealed that significant predictors of high school students' development of an interest in a health care career were gender (female), parent encouragement in math and science courses, parent college push, math and science selfefficacy beliefs, and the students' expectations for education after high school. These findings were consistent with studies that used the SCCT framework for the investigation 
of STEM career interest development in minority high school students. These studies found evidence that parental support of math and science, student math and science selfefficacy beliefs, and students' educational outcome expectations were related to interest to pursue a STEM career (Ferry, Fouad, \& Smith, 2000). Turner et al. (2004) found a positive association between maternal support of science and mathematics, student's educational expectations of college and students interest in a STEM field in a group of multiethnic sixth grade students. Constantine, Wallace, \& Kindaichi (2005) found that parental support was positively associated with African American adolescents' career interests and suggested the absence of this support would negatively affect African American adolescents in career decision making.

Although math and science teachers' push was not a significant predictor in this study's model, Arredondo and Castillo (2011) found that high school students' interest to pursue a STEM career was directly related to the student's math and science self-efficacy abilities that were fostered by classroom teachers. Lee, Min, and Mamerow (2015) found that males interest in STEM careers were shown to be most affected by teachers' educational expectations and encouragement while females choices to purse STEM were most affected by their parents. This evidence provides an interesting perspective for gender underrepresentation in fields of health care and STEM. Consistent with Lee, Min, and Mamerow (2015) findings, results of this study found parent encouragement and female gender as predicting a career interest in health care, whereas teacher encouragement and male gender were not significant predictors.

Additional findings of this study were that diverse (non-white) females were predictive of an interest in a health care career at high school graduation. This finding is 
consistent with the literature that more females, $78 \%$, make up the health professions workforce, however more males make up the dental and physician workforce. (U.S Department of Labor, 2017). Neilson and Jones (2012) found that minority high school students generally perceived nursing as lacking academic rigor and as a fall back career option for poor grades and lack of opportunity to pursue their desired career choice. Reiskin and Haussler (1994) found that both male and female culturally diverse urban high school students perceived nurses as working with their hands, working very hard, and were very busy, but were not powerful leaders, did not make decisions, and did not make a lot of money. However, these researchers (Reiskin \& Haussler, 1994) also found that African American and Latino female students had a more positive perception of nurses; as making a lot of money and being respected, than White and Asian female students.

\section{Mid-Pipeline - College}

\section{Health Care Major}

High school predictors of a student selection of a college major in health care was gender (female), parent push in science, student math and science self-efficacy beliefs, and students' expectations for education after high school. These findings are supported by previous studies. Fuchs and Miller (2012) found that the level of parent encouragement in science was positively related to college enrollment in a health care major. Their study revealed that only $7 \%$ of students whose parents provided a low level a medical or health professional preparation program than were young men. of science encouragement majored in a health care professional field compared to $19 \%$ of the students whose parents provided strong science encouragement (Fuch \& Miller, 2012). 
Their results were also consistent in relation to gender, whereas females were more likely to be enrolled in a college health care major than males (Fuch \& Miller, 2012). Encouragement by high school teachers and peers were not significant factors in this model and similarly, the literature has not reported significance in this factor either.

\section{End of Pipeline -Workforce}

\section{Nursing and Health Care Workforce}

The analysis revealed that the only significant high school influence in predicting entry into the nursing workforce was student self-efficacy beliefs in their math and science abilities. Other significant predictors of the model were being female and being of lower middle socioeconomic status. Consistent with current nursing workforce demographics, the nursing profession is predominantly female (NCSBN, 2013) and most college students come from similar socioeconomic status (NCES, 2016). The limited results found in the present study may be due to the small number of nurses (less than $2 \%$ ) who comprised the overall sample for the analysis. There was a larger sample size, $6 \%$ of the total population, for the analysis of entry into the workforce as a health care provider. This analysis revealed significance predictors of gender (female), parent math push, teacher college push, and student self-efficacy beliefs in their math and science abilities. No studies were found in a literature search to support the high school predictor variables however, there were no studies found that investigated these early high school predictors on entry into the health care workforce. Therefore, a unique finding of this study was that high school math/science teacher college push and student self-efficacy beliefs carried over the years of college to actual practice as a health care provider, a time span of 15-20 years. 
The last analysis in the study examined both high school health care career interest and college health care major as predictors of entry into the nursing workforce. Both predictors were significant, substantiating the notion that a health professions and nursing pipeline exists. It is also a helpful trajectory for strategic planning for educators and policy makers making decisions and directing resources on nursing workforce diversity initiatives.

\section{Implications of Findings}

The findings of this study reveal that early influences in the pre-collegiate pipeline predict important stages along the pathway to a career in nursing and health care. The findings of this study suggest that nursing workforce diversity initiatives targeted during the high school years would have lasting effects along the pipeline to entry into the workforce. These programs must robustly engage parents, math and science teachers, and focus on activities that contribute to students 'development of self-efficacy beliefs in their math and science abilities, and their expectations of attending college after high school. Studies found that student educational expectations for themselves have been associated with educational attainment, even after controlling for previous academic performance (Sommerfeld, 2016). Lent, Brown, and Hackett (1994) described the central concepts of SCCT was the learning experiences that directly influence self-efficacy beliefs and outcome expectations that drove career interest development, choice action, and performance in career domains. This study's findings were consistent with this assertion.

\section{Implications for Theory}

SCCT was a useful theoretical framework to guide this study. It was useful in understanding the influences of verbal persuasion on students' self-efficacy beliefs, and 
expected outcomes in nursing career development along the pipeline, even 15 year later. The framework should be used for further research in investigation of the influence of the other types of information from which students learn; past performance, vicarious learning, and physiological affects; and their influence on self -efficacy beliefs in math and science and outcome expectations along the nursing pipeline. When there is a better understanding of all learning experiences (sources of information) that influence selfefficacy beliefs in math and science and student outcome expectations, then targeted nursing work force strategies would potentially have more impact in diversifying the profession especially when there are limited resources.

\section{Implications for Research}

The distribution of race and ethnicity in the study sample was nationally representative at that the time of original recruitment, however the US population demographics have rapidly changed. (US Census Bureau, 1987; 2012). Therefore, replication of this study needs to be conducted with a sample representative of the current diversity of the U.S population, or a sample of minority participants only, for further investigation to determine the salience of these early high school and college predictors. The SCCT theoretical framework should guide this study because the framework explicitly considers culture and aspects of human diversity within the context of career development (Lent, \& Brow, 2013). Also consistent use of the SCCT framework allows for cross study comparisons that would add greater knowledge to the body of literature on this topic. Another interest for further study would be to investigate the gender influence of career interests as encouraged by parent and teachers. The difficulty of this type of study is that the percentage of minority nurses is small, and there is no longitudinal data- 
set for this purpose. One possible approach would be recruitment of a sample of minority nurses currently in the workforce and retrospectively collecting their early influences of encouragement they received from peers, parents and math and science teachers by questionnaire and interview. This study could also be conducted with nursing students who would be at a different stage along the pipeline and closer to the high school influences. Another possible study would be an in-depth qualitive study of minority nurses and students with a focus on their high school influences that may have guided their nursing career development. Also, as important as those who were successful along the pipeline, are students that were not. Qualitative and quantitative investigations should be explored in investigating the early influences, self-efficacy beliefs and outcome expectations that did not contribute to a nursing career.

\section{Implications for Nursing Practice and Education}

The findings of this study can guide nurse educators in creating nursing workforce diversity initiatives aimed at high school students. These programs should involve activities that promote student self-efficacy beliefs in math and science, and their expectations to attend college. Key to these programs is the targeted inclusion of math and science teachers, and parents. An initial first step of this inclusion needs to be education of the nursing profession itself and to dispel any negative or inaccurate perceptions they may have of the it (Manney, Fonza-Thomason, 2010). Accurate information and knowledge of the nursing profession may have influence on the gender bias seen in the nursing and health care workforce, where teachers and parents with inaccurate information may contribute to this gender bias. Further, nurse educators need to partner with math and science teachers in devolvement of creative curriculum modules 
that integrate health topics, classroom experiences and field trips aligned with core competencies required of secondary education standards and regulations. The literature has shown that career integration with high school coursework increases college admission rates for diverse students (Fletcher, 2012). Lastly through this partnership with math and science teachers, meaningful parent engagement can occur to promote parent encouragement in these subjects, shown to be essential in academic development and a nursing career trajectory. Early parent engagement by nurse educators in high school may also alleviate the emotional burden students experience from unsupportive parents in college nursing programs that contribute to high attrition rates. Lastly school nurse teachers should be very involved if not leading this partnership. They are registered nurses with a specialty certification in pediatric/ adolescent school health and education, are present in the school setting, and already play a prominent role.

\section{Implications for Policy}

There are implications for public policy from this research. First, the quality of public education is an important social determinant of health and not merely a pipeline to create more nurses. Therefore, nurses must be engaged with education policy at all levels, especially at discussions where career development policies are initiated. Engagement of nurses include, appointment to the state board of education, election to a town or city school committee, or serving on a board of an independent charter school. Often educators do not see their profession as gateway to health, therefore the comprehensive perspective of nurses working with families and communities is needed.

Another implication for policy is federal investment in nursing and health professions workforce programs. These programs are essential for the development of the 
nursing workforce as it continues its effort to increase diversity and fulfil new and expanded roles to meet the country's health care needs. A recently released proposed budget from the new administration significantly reduces funding for these programs by \$403 million dollars. Nurses must work with their congressional leaders to advocate for adequate funding for continued research, programs, and scholarships aimed at increasing the diversity of the nursing and health professions workforce. The nursing profession must partner with other like-minded healthcare professional organizations to accomplish this.

\section{Limitations of the Study}

This study's findings should be considered in conjunction with several limitations. First, the LSAY data set was not designed to specifically look at predictors of a career in nursing for minority and disadvantaged students. Therefore the study was limited to the existing LSAY variables, their measurement ,timeframe of sampling, data collection, and accuracy of the data.

Another limitation to the study that must be noted was the assumption that the same early high school predictors were constant along the nursing career continuum. It may be that predictors that were or were not significant in high school have a different influence in other points along the career continuum. For example, peer college push was significant only in predicting high school academic achievement in this study, step 1of the nursing pipeline, however the literature reported that peer college push was significant in college degree completion more so than parents push in step 2 of the pipeline (Sommerfeld, 2016). 


\section{Conclusion}

The process leading to diversifying the nursing and health care provider workforce is complex involving individual, psychological, and social influences all interacting together to shape the behavior along the pipeline to career development. Through the SCCT theoretical framework, a secondary data analyses of the LSAY revealed significant findings of early high school influences to guide nursing workforce diversity programs aimed at high school students. The findings suggest that programs must encompass strategies that foster student self-efficacy beliefs in their math and science abilities and expectations to attend college. Parents and teachers' encouragement in math and science also had lasting effects for students in pursuit of a health care career several years after high school. Nurse educators cannot accomplish this alone but must work collaboratively with math and science high school teachers to integrate these programs within their classrooms. Lastly, nurses must advocate for federal investment in nursing workforce development programs so the changing health care needs of this county are met, including a nursing and health professions workforce that mirrors the diversity of the patients for whom they provide care. 


\section{Appendix A: URI IRB Letter}

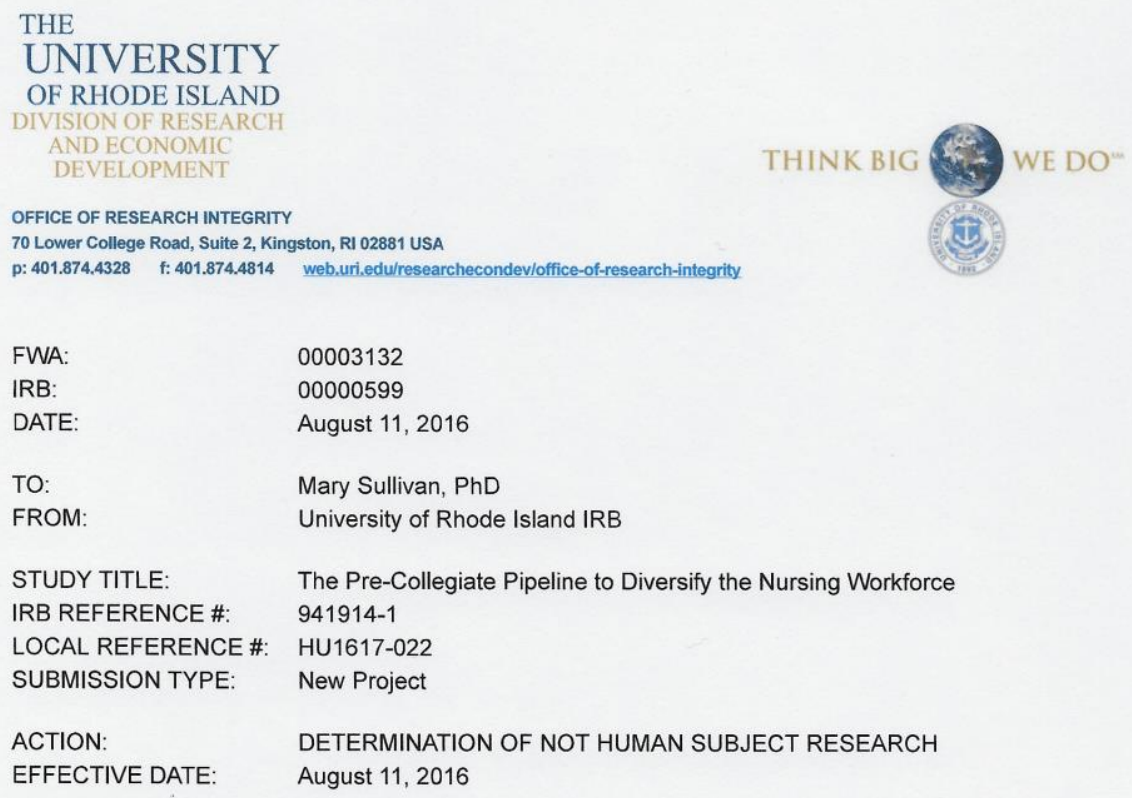

Thank you for your submission of New Project materials for this research study. The University of Rhode Island IRB has determined this project does not meet the definition of human subject research under the purview of federal regulation 45 CFR 46 regarding human subject research at this time. Therefore, your project does not require Institutional Review Board (IRB) oversight. Any changes in focus of this project will require further review of the IRB.

If you have any questions, please contact us by email at researchintegrity@etal.uri.edu. Please include your study title and reference number in all correspondence with this office.

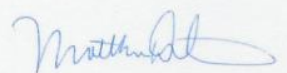

Matthew Delmonico, Ph.D., MPH IRB Chair 
Appendix B: SCCT Framework and Study Variables

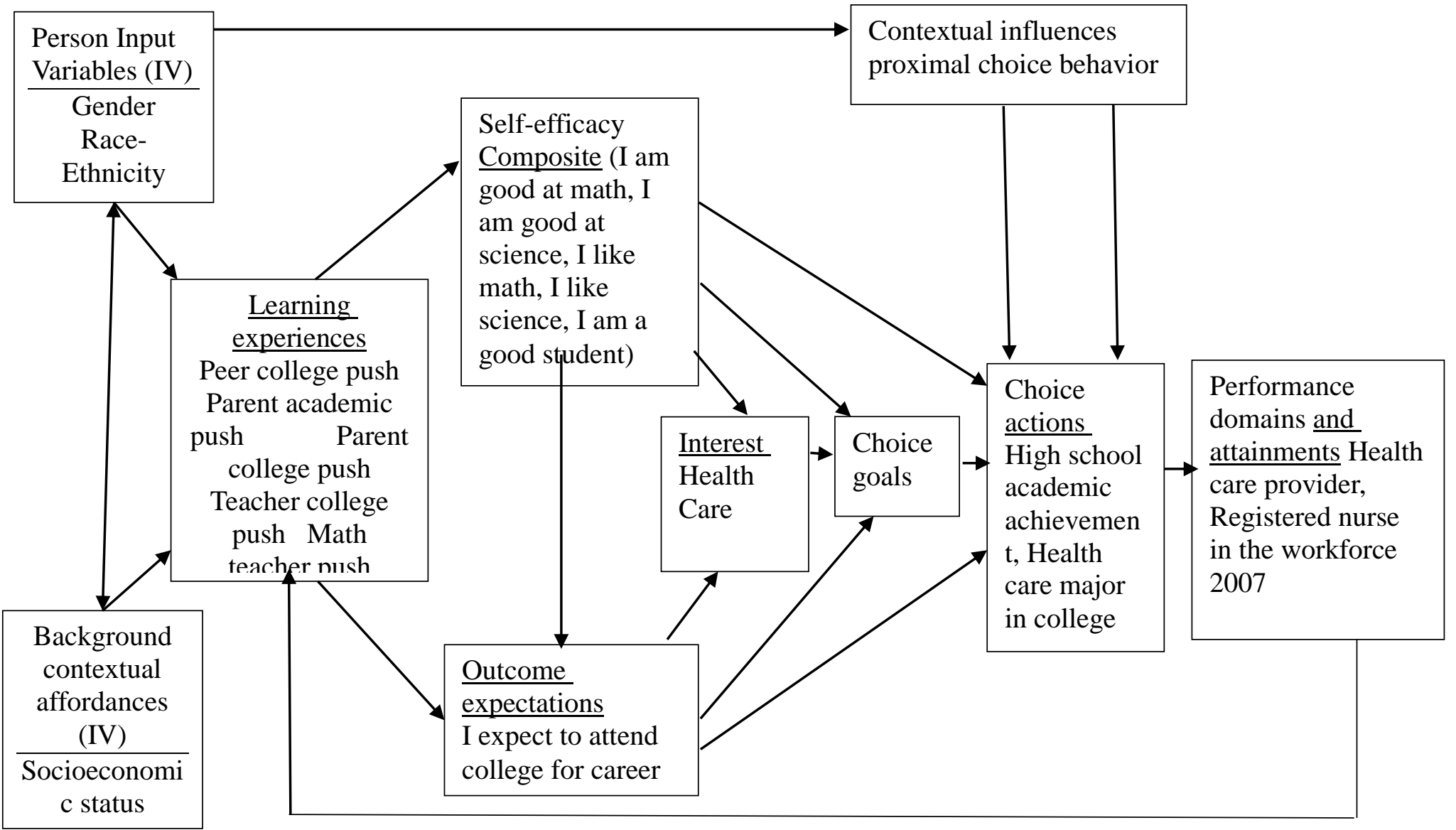


Appendix C: Correlation Table

\begin{tabular}{|c|c|c|c|c|c|c|c|c|c|c|c|c|c|c|c|c|c|c|}
\hline & $\begin{array}{l}\text { High school } \\
\text { acheivment }\end{array}$ & $\begin{array}{c}\text { Interest in } \\
\text { health } \\
\text { care } \\
\text { career } \\
\end{array}$ & $\begin{array}{c}\text { Health } \\
\text { care } \\
\text { college } \\
\text { major } \\
\end{array}$ & $\begin{array}{c}\text { Health Care } \\
\text { occupation } \\
2007\end{array}$ & $\begin{array}{l}\text { RN } \\
\text { Occupation } \\
2007\end{array}$ & Gender & $\begin{array}{c}\text { Race/Ethn } \\
\text { city }\end{array}$ & SES & $\begin{array}{c}\text { Peer } \\
\text { college } \\
\text { push }\end{array}$ & $\begin{array}{c}\text { Parent } \\
\text { academic } \\
\text { push }\end{array}$ & $\begin{array}{c}\text { Parent } \\
\text { college } \\
\text { push }\end{array}$ & $\begin{array}{c}\text { Parent } \\
\text { math push }\end{array}$ & $\begin{array}{l}\text { Parent } \\
\text { sciencee } \\
\text { push }\end{array}$ & $\begin{array}{l}\text { Teacher } \\
\text { college } \\
\text { push }\end{array}$ & $\begin{array}{l}\text { Math } \\
\text { teacher } \\
\text { push }\end{array}$ & $\begin{array}{l}\text { Science } \\
\text { teacher } \\
\text { push }\end{array}$ & $\begin{array}{l}\text { Self- } \\
\text { efficacy }\end{array}$ & $\begin{array}{c}\text { Student } \\
\text { education } \\
\text { expectations }\end{array}$ \\
\hline $\begin{array}{l}\text { High school } \\
\text { acheivment }\end{array}$ & 1 & & & & & & & & & & & & & & & & & \\
\hline $\begin{array}{l}\text { Interest in health } \\
\text { care career }\end{array}$ & $.118^{\prime \prime}$ & 1 & & & & & & & & & & & & & & & & \\
\hline $\begin{array}{l}\text { Health care college } \\
\text { major }\end{array}$ & $.096^{\prime \prime}$ & $.376^{\prime \prime}$ & 1 & & & & & & & & & & & & & & & \\
\hline $\begin{array}{l}\text { Health Care } \\
\text { occupation } 2007\end{array}$ & $.048^{\prime \prime}$ & $.267^{\prime \prime}$ & $.230^{\circ}$ & 1 & & & & & & & & & & & & & & \\
\hline $\begin{array}{l}\text { RN Occupation } \\
2007\end{array}$ & $.039^{\circ}$ & $.191^{\prime \prime}$ & $.208^{\prime \prime}$ & $.579^{\prime \prime}$ & 1 & & & & & & & & & & & & & \\
\hline Gender & .021 & $-.125^{\prime \prime}$ & $-.090^{\circ}$ & $-.101^{\prime \prime}$ & $-.097^{\prime \prime}$ & 1 & & & & & & & & & & & & \\
\hline Race/Ethncity & .205" & .017 & .006 & .020 & .013 & .004 & 1 & & & & & & & & & & & \\
\hline SES & $.319^{\prime \prime}$ & $.105^{\prime \prime}$ & $.064^{\prime \prime}$ & .015 & -.014 & $.037^{\circ}$ & $.113^{\prime \prime}$ & 1 & & & & & & & & & & \\
\hline Peer college push & $.415^{\circ}$ & $.183^{\prime \prime}$ & $.106^{\prime \prime}$ & $.036^{\circ}$ & .030 & $-.143^{*}$ & $.069^{\prime \prime}$ & $.215^{\prime \prime}$ & 1 & & & & & & & & & \\
\hline $\begin{array}{l}\text { Parent academic } \\
\text { push }\end{array}$ & $.111^{\prime \prime}$ & $.059^{\prime \prime}$ & $.048^{\prime \prime}$ & .013 & .001 & -.030 & .010 & $.211^{\prime \prime}$ & $.192^{\prime \prime}$ & 1 & & & & & & & & \\
\hline $\begin{array}{l}\text { Parent college } \\
\text { push }\end{array}$ & $.313^{\prime \prime}$ & $.171^{\prime \prime}$ & $.084^{\prime \prime}$ & $.061^{\prime \prime}$ & .016 & -.015 & .019 & $.300^{\prime \prime}$ & $.328^{\prime \prime}$ & $.214^{\prime \prime}$ & 1 & 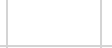 & & & & & & \\
\hline Parent math push & $.256^{\prime \prime}$ & $.070^{\prime \prime}$ & $.052^{\prime \prime}$ & .003 & -.003 & $.036^{\circ}$ & $.046^{\prime \prime}$ & $.168^{*}$ & $.229^{\prime \prime}$ & $.442^{\prime \prime}$ & $.214^{\prime \prime}$ & 1 & & & & & & \\
\hline $\begin{array}{l}\text { Parent science } \\
\text { push }\end{array}$ & $.305^{\prime \prime}$ & $.163^{\prime \prime}$ & $.106^{\prime \prime}$ & $.041^{\prime \prime}$ & .010 & $.056^{\prime \prime}$ & $.045^{\prime \prime}$ & $.168^{\prime \prime}$ & $.317^{\prime \prime}$ & $.294^{\prime \prime}$ & $.228^{\prime \prime}$ & $.562^{\prime \prime}$ & 1 & & & & & \\
\hline $\begin{array}{l}\text { Teacher college } \\
\text { push }\end{array}$ & $.384^{\prime \prime}$ & $.157^{\prime \prime}$ & $.119^{\prime \prime}$ & $.079^{\prime \prime}$ & $.036^{\circ}$ & $.038^{\circ}$ & $.041^{\circ}$ & $.246^{*}$ & $.449^{\prime \prime}$ & $.216^{\prime \prime}$ & $.307^{\prime \prime}$ & $.296^{\prime \prime}$ & $.337^{\prime \prime}$ & 1 & & & & \\
\hline Math teacher push & $.316^{\prime \prime}$ & $.107^{\prime \prime}$ & $.085^{\prime \prime}$ & $.063^{\prime \prime}$ & $.051^{\prime \prime}$ & $-.082^{*}$ & $.047^{\prime \prime}$ & $.089^{\prime \prime}$ & $.400^{\prime \prime}$ & $.195^{\prime \prime}$ & $.183^{\prime \prime}$ & $.317^{\prime \prime}$ & $.327^{\prime \prime}$ & $.400^{\prime \prime}$ & 1 & & & \\
\hline $\begin{array}{l}\text { Science teacher } \\
\text { push }\end{array}$ & $.281^{\prime \prime}$ & $.119^{\prime \prime}$ & $.090^{\circ}$ & $.056^{\prime \prime}$ & $.047^{\circ}$ & $-.063^{\prime \prime}$ & $.050^{\prime \prime}$ & $.096^{*}$ & $.392^{\prime \prime}$ & $.153^{\prime \prime}$ & $.155^{\circ}$ & $.226^{\prime \prime}$ & $.418^{\prime \prime}$ & $.317^{\prime \prime}$ & $.503^{\prime \prime}$ & 1 & & \\
\hline Self-efficacy & $.373^{\prime \prime}$ & $.145^{\prime \prime}$ & $.113^{\prime \prime}$ & $.098^{\prime \prime}$ & $.059^{\prime \prime}$ & $.152^{\prime \prime}$ & .037 & $.101^{\prime \prime}$ & $.216^{*}$ & $.155^{\circ}$ & $.148^{\prime \prime}$ & $.258^{\prime \prime}$ & $.281^{\prime}$ & $.406^{\prime \prime}$ & $.270^{\circ}$ & $.213^{\prime \prime}$ & 1 & \\
\hline $\begin{array}{l}\text { Student education } \\
\text { expections }\end{array}$ & $.473^{\prime \prime}$ & $.244^{\prime \prime}$ & $.137^{\prime \prime}$ & $.070^{\circ}$ & $.041^{\circ}$ & $-.071^{\prime \prime}$ & $.075^{\prime \prime}$ & $.374^{\prime \prime}$ & $.471^{\prime \prime}$ & $.284^{\prime \prime}$ & $.472^{\prime \prime}$ & $.259^{\prime \prime}$ & $.287^{\prime \prime}$ & $.429^{\prime \prime}$ & $.257^{\prime \prime}$ & $.232^{\prime \prime}$ & $.293^{\prime \prime}$ & 1 \\
\hline
\end{tabular}




\section{Bibliography}

Adelman, C. (2006). The toolbox revisited: Paths to degree completion from high school through college. Washington, DC: US Department of Education.

Afeiche, M., Peterson, K. E., Sanchezz, B. N., Schnaas, L., Cantonwine, D., Ettinger, A. S., Tellez-Rojo, M. M. (2012). Windows of lead exposure sensitivity’ attained height, and body max index at 48 months. Journal of Pediatrics, 160(6), 10441049. http://dx.doi.org/ 10.1016/j.jpeds.2011.12.022

Agency for Healthcare Research and Quality. (2015). 2014 National healthcare quality and disparities report (AHRQ Publication No.15-0007). Washington, DC: Government Printing Office.

Agency for Healthcare Research and Quality. (2015). 2015 National healthcare quality and disparities report and 5th anniversary update on the national quality strategy (AHRQ Publication No. 16-0015). Washington, DC: Government Printing Office.

Agency for Healthcare Research and Quality. (2016). Agency for healthcare research and quality: Division of priority populations (AHRQ Pub. No. 16-M009-EF). Washington, DC: Government Printing Office.

Allen, L. (2008). The nursing shortage continues as the faculty shortage grows. Nursing Economics, 26(1), 35-40.

Ali, S. R., \& Menke, K. A. (2014). Rural Latino youth career development: An application of social cognitive career theory. The Career Development Quarterly, 62(2), 175-186. http://dx.doi.org/10.1002/j.2161-0045.2014.00078.x 
Amaro, D. J., Abrian-Yago, K., \& Yoder, M. (2006). Perceived barriers for ethnically diverse students in nursing programs. Journal of Nursing Education, 45(7), 247254.

American Association of Colleges of Nursing. (2015). The changing landscape: Nursing student diversity on the rise [Policy Brief]. Retrieved from http://www.aacn.nche.edu/government-affairs/Student-Diversity-FS.pdf

Archbald, D., \& Farley-Ripple, E. N. (2012). Predictors of placement in lower level versus higher level of high school mathematics. The High School Journal, 96(1), $33-51$.

Arredondo, P., \& Castillo, L. G. (2011). Latina/o student achievement: A collaborative mission of professional associations of higher education. Journal of Hispanic Higher Education, 10(1), 6-17.

Bach, P. B., Pham, H. H., Schrag, D., Tate, R. C., \& Hargraves, J. L. (2004). Primary care physicians who treat Black and Whites. New England Journal of Medicine, $351(6), 575-584$.

Ballantyne, J. E. (2008). Cultural competency: Highlighting of the work of the American Association of Colleges of Nursing-California Endowment Advisory Group. Journal of Professional Nursing, 24(3), 133-134.

Bandura, A. (1971). Social learning theory. New York: General Learning Press.

Bandura, A. (1977). Self-efficacy: Toward a unifying theory of behavioral change. Psychological Review, 84(2), 191-215.

Bandura, A. (1986). Social foundations of thought and action: A social cognitive theory. Englewood Cliffs, NJ: Prentice-Hall. 
Banister, G., Bowen-Brady, H. M., \& Winfrey, M. E. (2014). Using career nurse mentors to support minority nursing students and facilitate their transition to practice. Journal of Professional Nursing, 30(4), 317-325.

Beacham, T., Askew, R. W., \& Williams, P. R. (2009). Strategies to increase racial/ethnic student participation in the nursing profession. ABNF Journal, 20(3), 69-72.

Betz, N. E., \& Hackett, G. (1981). The relationship of career-related self-efficacy expectations to perceived career options in college women and men. Journal of Counseling Psychology, 28(5), 399-410.

Betz, N. E., \& Hackett, G. (2006). Career self-efficacy theory: Back to the future. Journal of Career Assessment, 14(1), 3-11. http://dx.doi.org/10.117/1069072705281347

Bodenheimer, T., \& Bauer, L. (2016). Rethinking the primary care workforce --- An expanded role for nurses. The New England Journal of Medicine, 375, 1015-1017. http://dx.doi.org/ 10.1056/NEJMp1606869

Bond, M. L., Gray, J. R., Baxley, S., Cason, C. L., \& Denke, L. (2008). Voices of Hispanic students in baccalaureate nursing programs: Are we listening?. Nursing Education Perspectives, 29(3), 136-142.

Bordes-Edgar, V., Arrendond, P., Kurpius, S. R., \& Rund, J. (2011). A longitudinal analysis of Latina/o student's academic persistence. Journal of Hispanic Higher Education, 10(4), 358-368.

Bovbjerg, R., \& McDonald, E. (2014). Literature review: Healthcare occupational training and support programs under the ACA-background and implications for evaluating HPOG (OPRE Report No. 2014-29). Washington, DC: Government Printing Office. 
Braveman, P. (2006). Health disparities and health equity: Concepts and measurement. Annual Review of Public Health, 27, 167-194.

Braveman, P. (2014). What are health disparities and health equity? We need to be clear. Public Health Reports, 129(Suppl 2), 5-8.

Braveman, P. A., Kumanyika, S., Fielding, J., LaVeist, T., Borrell, L. N., Manderscheid, R., \& Troutman, A. (2011). Health disparities and health equity: The issue is justice. American Journal of Public Health, 101(S1), 149-155.

Braveman, P., \& Gottlieb, L. (2014). The social determinants of health: It's time to consider the causes of the causes. Public Health Reports, 129(Suppl 2), 19-31.

Brotherton, S. E., Stoddard, J. J., \& Tang, S. S. (2000). Minority and nonminority pediatricians' care of minority and poor children. Archives of Pediatric and Adolescent Medicine, 154(9), 912-917.

Byars, A., \& Hackett, G. (1998). Applications of social cognitive career theory to the career development of women of color. Applied and Preventive Psychology, 7(4), 255-267.

Carter-Pokras, O., \& Baquet, C. (2002). What is a "health disparity"? Public Health Reports, 117, 426-434.

Chang, Y., \& Edwards, J. K. (2015). Examining the relationships among self-efficacy, coping, and job satisfaction using social cognitive career theory: An SEM analysis. Journal of Career Assessment, 23(1), 35-47.

Childs, G., Jones, R., Nugent, K., \& Cook, P. (2004). Retention of African-American students in baccalaureate nursing programs: Are we doing enough? ABNF Journal, 20(2), 129-133. 
Chuang, Y., Cubbin, C., Ahn, D., \& Winkleby, M. A. (2005). Effects of neighborhood socioeconomic status and convenience store concentration on individual level smoking. Journal of Epidemiology and Community Health, 59(7), 568-573.

Cohen, J. A., Palumbo, M. V., Rambur, B., \& Mongeon, J. (2004, May-June, 2004). Middle school students' perceptions of an ideal career and a career in nursing. Journal of Professional Nursing, 20(3), 202-210.

Cohen, J. J., Gabriel, B. A., \& Terrel, C. (2002). The case for diversity in the health care workforce. Health Affairs, 21(5), 90-102.

Condon, V. M., Morgan, C. J., Miller, E. W., Mamier, I., Zimmerman, G. J., \& Mazhar, W. (2013). A program to enhance recruitment and retention of disadvantaged and ethnically diverse baccalaureate nursing students. Journal of Transcultural Nursing, 24(2), 397-407.

Constantine, M. G., Wallace, B. C., \& Kindaichi, M. M. (2005). Examining contextual factors in the career decision status of African American Adolescents. Journal of Career Assessment, 13(3), 307-319. http://dx.doi.org/10.1177/1069072705274960

Cooper, L. A., Roter, D. L., Johnson, R. L., Ford, D. E., Steinwachs, D. M., \& Powe, N. R. (2003). Patient-centered communication, ratings, and concordance of patient and physician race. Annals of Internal Medicine, 139(11), 907-915.

Cooper-Patrick, L., Gallo, L., \& Gonzalez, J. (1999). Race, gender, and partnership in the patient-physician relationship. Journal of the American Medical Association, 282(6), 583-589. 
Crede, M., \& Kuncel, N. R. (2008). Study habits, skills, and attitudes: The third pillar supporting collegiate academic performance. Perspectives on Psychological Science, 3(6), 425-453.

Dapremont, J. A. (2013). A review of minority recruitment and retention models implemented in undergraduate nursing programs. Journal of Nursing Education and Practice, 3(2),112-119.

Degazon, C. E., \& Mancha, C. (2012). Changing the face of nursing: Reducing ethnic and racial disparities in health. Family and Community Health, 35(1), 5-15.

Dehlendorf, C., Bryant, A. S., Huddleston, H. G., Jacoby, V. L., \& Fujimoto, V. Y. (2010). Health disparities: Definitions and measurements. American Journal of Obstetrics \& Gynecology, 202(3), 212-213. http://dx.doi.org/10.1016/j.ajog.2009.12.003

Engberg, M. E., \& Wolniak, G. C. (2010). Examining the effects of high school contexts on post-secondary enrollment. Research in Higher Education, 51(2), 132-153.

Ferry, T. R., Fouad, N. A., \& Smith, P. L. (2000). The role of family context in social cognitive model for career-related choice behavior: A math and science perspective. Journal of Vocational Behavior, 57(3), 348-364.

Flores, L. Y., Navarro, R. L., \& Ali, S. R. (2017). The state of SCCT research in relation to social class: Future Directions. Journal of Career Assessment, 25(1), 6-23. http://dx.doi.org/10.1177/1069072716658649

Fouad, N. A., \& Santana, M. C. (2017). SCCT and underrepresented populations in STEM fields: Moving the needle. Journal of Career Assessment, 25(1), 24-39. http://dx.doi.org/10.1177/1069072716658324 
Fuchs, B. A., \& Miller, J. D. (2012). Pathways to careers in medicine and health. Peabody Journal of Education, 87(1), 62-76. http://dx.doi.org/10.1080/0161956X.2012.642271

Garriott, P. O., Flores, L. Y., Prabhakar, B., Mazzotta, E. C., Liskov, A. C., \& Shapiro, J. E. (2014). Parental support and underrepresented students' math/science interests: The mediating role of learning experiences. Journal of Career Assessment, 22(4), 627-641. http://dx.doi.org/10.1177/1069072713514933

Gillis, C. L., Powell, D. L., \& Carter, B. (2010). Recruiting and retaining a diverse workforce in nursing: from evidence to best practices to policy. Policy, Politics \& Nursing Practice, 11(4), 294-301.

Gloria, A., Castellanos, J., Lopez, A. G., \& Rosales, R. (2005). An examination of academic nonpersistence decisions of Latino undergraduates. Hispanic Journal of Behavioral Sciences, 27(2), 202-223.

Gloria, A., \& Hird, J. (1999). Influences of ethnic and nonethnic variables on career decision self-efficacy of college students. Career Development Quarterly, 48, $157-174$

Gordon-Larson, P., Nelson, M. C., Page, P., \& Popkin, B. M. (2006). Inequality in the built environment underlies key health disparities in physical activity and obesity. Pediatrics, 117(2), 417-424.

Gray, B., \& Sroddard, J. J. (1997). Patient-physician pairing: Does racial and ethnic congruity influence selection of a regular physician? Journal of Community Health, 22(4), 247-259. 
Hackett, G., \& Betz, N. E. (1981). A self-efficacy approach to the career development of women. Journal of Vocational Behavior, 18(3), 326-336.

Harlow, L. L. (2014). The essence of multivariate thinking (2nd ed.). New York, NY: Routledge.

Health Resources and Services Administration, Bureau of Health Professions. (2006). The rationale for diversity in the health professions: A review of evidence (DHHS Publication No.03-0285P). Washington, DC: Government Printing Office.

Ing, M., \& Nyland-Gibson, K. (2013). Linking early science and mathematics attitudes to long-term science, technology, engineering, and mathematics career attainment: Latent class analysis with proximal and distal outcomes. Education Research and Evaluation, 19(6), 510-524. http://dx.doi.org/10.1080/13803611.2013.806218

Institute of Medicine. (2002). Unequal treatment: Confronting racial and ethnic disparities in health care. Washington, DC: Government Printing Office. Institute of Medicine. (2003). In the nation's compelling interest: Ensuring diversity in the health-care workforce. Washington, DC: Government Printing Office.

Institute of Medicine. (2011). The future of nursing: Leading change, advancing health. Washington, DC: Government Printing Office.

Kindermann, T. (2007). Effects of naturally existing peer groups on changes in academic engagement in a cohort of sixth graders. Child Development, 78(4), 1186-1203.

Komaromy, M., Grumbach, K., Drake, M., Vranizan, K., Lurie, N., Keane, D., \& Bindman, A. B. (1996). The role of Black and Hispanic physicians in providing health care for underserved populations. New England Journal of Medicine, 334(20), 1305-1310. 
Lanphear, B., Kahn, R. S., Berger, O., Auinger, P., Bortnick, S. M., \& Nahhas, R. W. (2001). Contribution of residential exposures to asthma in US children and adolescents. Pediatrics, 107(6), 1-7. http://dx.doi.org/10.1542/peds.107.6.e98

LaVeist, T. A., \& Carroll, T. (2002). Race of physician and satisfaction with care among African-American patients. Journal of the National Medical Association, 94(11), 937-943.

LaVeist, T. A., \& Nuru-Jeter, A. (2002). Is doctor patient race-concordance associated with greater satisfaction with care? Journal of Health and Social Behavior, 43(3), 296-306.

LaVeist, T. A., \& Pierre, G. (2014). Integrating the 3Ds-social determinants, health disparities, and health-care workforce diversity. Public Health Reports, 129(Suppl 2), 9-14.

Lee, C. (1984). Predicting the career choice attitudes of rural Black, White, and Native American high school students. Vocational Guidance Quarterly, 32(3), 177-184.

Lee, S. W., Min, S., \& Mamerow, G. P. (2015). Pygmalion in the classroom and the home: Expectations' role in the pipeline to STEMM. Teachers College Record, 117(9), 1-40.

Lent, R. W., \& Brown, S. D. (2006). Integrating person and situation perspectives on work satisfaction: A social-cognitive view. Journal of Vocational Behavior, 69(2), 236-247. http://dx.doi.org/10.1016/j.jvb.2006.02.006

Lent, R. W., \& Brown, S. D. (2013). Social cognitive model of career self-management: Toward a unifying view of adaptive career behavior across the lifespan. Journal of Counseling Psychology, 60(4), 557-568. http://dx.doi.org/10.1037/a0033446 
Lent, R. W., Brown, S. D., \& Hackett, G. (1994). Toward a unifying social cognitive theory of career and academic interest, choice, and performance. Journal of Vocational Behavior, 45(1), 79-122.

Lent, R. W., Hackett, G., \& Brown, S. D. (2000). Contextual supports and barriers to career choice: A social cognitive analysis. Journal of Counseling Psychology, 47(1), 36-49.

Lewis, T. (2007). Social inequality in education: A constraint on an American high-skills future. Curriculum Inquiry, 37(4), 329-349.

Lidsky, T. I., \& Schneider, J. S. (2003). Lead neurotoxicity in children: Basic mechanisms and clinical correlates. Brain: A Journal of Neurology, 126, 5-19. http://dx.doi.org/ 10.1093/brain/awg014

Loftin, C., Newman, S. D., Dumas, B. P., Gilden, G., \& Bond, M. (2012). Perceived barriers to success for minority nursing students: An integrative review. International Scholarly Research Network, 2012(2012), 1-9.

Loftus, J., \& Duty, S. (2010). Education ethnic minority students for the nursing workforce: Facilitators and barriers to success. Journal of the National Black Nurses Association, 21(1), 7-16.

Louis, R., \& Mistel, J. (2012). The differences in scores and self-efficacy by student gender in mathematics and science. International Journal of Science and Mathematics Education, 10(5), 116-1190.

Lynch, A. D., Lerner, R. M., \& Leventhal, T. (2013). Adolescent academic achievement and school engagement: An examination of the role of school-wide peer culture. Journal of Youth and Adolescence, 42(1), 6-9. 
Major, J. M. (2009). Self-efficacy and academic success among ethnically diverse firstgeneration community college students. Journal of Diversity in Higher Education, 2(4), 243-250.

Marrast, L. M., Zallman, L., \& Woolhandler, S. (2014). Minority physicians' role in the care of underserved patients: Diversifying the physician workforce may be key in addressing health disparities. Journal of American Medical Association Internal Medicine, 174(2), 289-291. http://dx.doi.org/10.1001/jamainternmed.2013.12756

Mau, W. J. (2016). Characteristics of US students that pursued a STEM major and facts that predicted their persistence in degree completion. Universal Journal of Educational Research, 4(6), 1495-1500. http://dx.doi.org/10.13189/ujer.2016.040630

McLain, R. M., Fifolt, M., Dawson, M. A., Su, W., Milligan, G., Davis, S., \& Hites, L. (2017). Student success survey: Supporting academic success for at-risk nursing students through early intervention. Nurse Educator, 42(1), 33-37.

Miller, J. D. (2014). Longitudinal Study of American Youth, 1987-1994, 2007-2011. Retrieved from http://doi.org.uri.idm.oclc.org/10.3886/ICPSR30263.v5

Mitchell, F. M. (2015). Racial and ethnic health disparities in an era of health care reform. Health \& Social Work, 40(3), 66-74.

Moller, S., Banerjee, N., Bottia, M. C., Stearns, E., Mickelson, R. A., Dancy, M., ... Valentino, L. (2015). Moving Latino/a students into STEM majors in college: The role of teachers and professional communities in secondary schools. Journal of Hispanic Education, 14(1), 3-33. http://dx.doi.org/10.1177/1538192714540533 
Moy, E., \& Bartman, B. A. (1995). Physician race and care of minority and medically indigent patients. Journal of the American Medical Association, 273(19), 15151520.

Moy, E., \& Freeman, W. (2014). Federal investments to eliminate racial/ethnic healthcare disparities. Public Health Reports, 129(Suppl 2), 1-12.

National Center for Education Statistics. (2010). Status and trends in the education of racial and ethnic groups (NCES 2010-015). Washington, DC: Government Printing Office.

National Center for Education Statistics. (2016). Status and trends in the education of racial and ethnic groups 2016 (NCES2016-007). Washington, DC: Government Printing Office.

National Council of State Boards of Nursing. (2013). The National Council of State Boards of Nursing and the Forum of State Nursing Workforce Centers 2013 National Workforce Survey of RNs. Journal of Nursing Regulation: 4 (suppl. National Institute of Health. (2005). Addressing disparities: the NIH program for action. What are health disparities? Washington, DC: Government Printing Office.

Navarro, R. L., Flores, L. Y., \& Worthington, R. L. (2007). Mexican American middle school students' goal intentions in mathematics and science: A test of social cognitive career theory. Journal of Counseling Psychology, 54(3), 320-335.

Ojeda, L., \& Flores, L. Y. (2011). Social cognitive predictors of Mexican American men's college students' academic and life satisfaction. Journal of Counseling Psychology, 58(1), 61-71. 
Olle, C. D., \& Fouad, N. A. (2015). Parental support, critical consciousness, and agency in career decision making for urban students. Journal of Career Assessment, 23(4), 533-544.

Parker, M. M., Fernanez, A., Moffet, H. H., Grant, R. W., Torreblanca, A., \& Karter, A. J. (2017). Association of patient-physician language concordance and glycemic control for limited-English proficiency Latinos with type 2 diabetes. Journal of the American Medical Association Internal Medicine, 177(3), 380-387. http://dx.doi.org/10.1001/jamainternmed.2016.8648

Perez-Stable, E. J., Napoles-Springer, A., \& Miramontes, J. M. (1998). The effects of ethnicity and language on medical outcomes of patients with hypertension or diabetes. Medical Care, 35(12), 1212-1219.

Rabinowitz, H. K., Diamond, J. J., \& Gayle, J. A. (2000). The impact of multiple predictors on generalist physicians' care of underserved populations. American Journal of Public Health, 90(8), 1225-1228.

Saha, S., Komaromy, M., Koepell, T. D., \& Bindman, A. B. (1999). Patient-physician racial concordance and the perceived quality and use of health care. Journal of the American Medical Association, 159(9), 997-1004.

Seago, J. A., \& Spetz, J. (2005). California's minority majority and the white face of nursing. Journal of Nursing Education, 44(12), 555-562.

Smith, J., Stern, K., \& Shatrova, Z. (2008). Factors inhibiting Hispanic parents' school involvement. Rural Educator, 29(2), 8-13. 
Sohler, N. L., Fitzpatrick, L. K., Lindsay, R. G., Anastos, K., \& Cunningham, C. O. (2007). Does patient-provider racial/ethnic concordance influence ratings of trust in people with HIV infection? Aids and Behavior, 11(6), 884-896.

Sommerfeld, A. K. (2016). Education as a collective accomplishment: how personal, peer, and parent expectations interact to promote degree attainment. Social Psychology of Education, 19(2), 345-366. http://dx.doi.org/10.1007/s11218-0159325-7

Spera, C., Wentzel, K. R., \& Matto, H. C. (2009). Parental aspirations for their children's educational attainment: Relations to ethnicity, parental education, children's academic performance, and parental perceptions of school climate. Journal of Youth and Adolescence, 38(8), 1140-1152.

Stinson, M. H., \& Thurston, N. K. (2002). Racial matching among African American and Hispanic patients and physicians. The Journal of Human Resources, 37(2), 410428.

The Sullivan Commission. (2004). Mission persons: Minorities in the health professions. Washington, DC: Sullivan Commission.

Turner, S. L., \& Conkel Ziebel, J. L. (2011). The career beliefs of inner-city adolescents. Professional School Counseling, 15(1), 1-14.

Turner, S.L., Lapan, R.T. (2002) Career self-efficacy and perceptions of parent support in adolescent career development. Career Development Quarterly, 51(1), 41-52.

Turner, S. L., Steward, J. C., \& Lapan, R. T. (2004). Family factors associated with sixthgrade adolescents' math and science career interests. Career Development Quarterly, 53(1), 41-52. 
Ubri, P., \& Artiga, S. (2016). Disparities in health and health Care: Five key questions and answers [Issue brief]. Retrieved from The Henry J. Keiser Family Foundation: http://files.kff.org/attachment/Issue-Brief-Disparities-in-Health-andHealth-Care-Five-Key-Questions-and-Answers

US Census Bureau. (2012). 2010 census summary file. Washington, DC: Government Printing Office.

US Census Bureau, (1970). 1970 industry and occupation code list. Retrieved from US Census Bureau website: https://www.census.gov/people/io/methodology/ US Department of Education, National Center of Education Statistics. (2016). The condition of education 2016 (NCES2016-144). Washington, DC: Government Printing Office.

US Department of Health and Human Services. (2000). Healthy people 2010. Washington, DC: Government Printing Office.

US Department of Health and Human Services. (2010). Healthy people 2020. Washington, DC: Government Printing Office.

US Department of Health and Human Services, Health Resources Administration, National Center for Health Workforce Analysis. (2014). Sex, race and ethnic diversity of the US health occupations (2010-2012). Washington, DC: Government Printing Office.

US Department of Labor. (2017). Labor force statistics from current population survey. Washington, DC: Government Printing Office.

Villarruel, A. (2011). Diversity matters! Reframing the dialogue. Nursing Outlook, 59(1), 4-5. 
Villarruel, A. M., Canales, M., \& Torres, S. (2001). Bridges and barriers: Educational mobility of Hispanic nurses. Journal of Nursing Education, 40(6), 245-251.

Whitehead, M. (1992). The concepts and principles of equity and health. International Journal of Health Services, 22(3), 429-445.

Whitehead, M., \& Dahlgren, G. (2006). Concepts and principles for tackling social inequities in health; leveling up part 1. Copenhagen: World Health Organization Regional Office for Europe.

Woolf, S. H., \& Braveman, P. (2012). Where health disparities begin: The role of social and economic determinants and why current policies may make matters worse. Health Affairs, 30(10), 1852-1859.

World Health Organization. (2008). Closing the gap in a generation: Health equity through action on the social determinates of health. Geneva: World Health Organization.

World Health Organization. (n.d.). Social determinants of health. Retrieved from http://www.who.int/social_determinants/sdh_definition/en/ 